\title{
MAS ALLÁ DE LOS CRITERIOS DISCIPLINARIOS. UN ESTUDIO ETNOGRÁFICO SOBRE LAS DECISIONES DE ADMISIÓN EN UN PABELLÓN PSIQUIÁTRICO-PENITENCIARIO EN LA REPÚBLICA ARGENTINA
}

\section{Mercedes ROJAS MACHADO ${ }^{1}$}

\section{Resumen}

El presente trabajo se propone analizar la injerencia de requerimientos institucionales y valoraciones afectivas en la práctica cotidiana de un equipo civil especializado en salud mental dentro de una cárcel federal de máxima seguridad en la República Argentina. A tales fines se indaga la instancia de admisión, en la que profesionales de salud deciden la incorporación de internos penitenciarios tipificados con algún padecimiento mental dentro de su dispositivo de tratamiento, para dar cuenta de los factores que exceden los criterios disciplinarios y definen la relación entre lógicas psiquiátrico-terapéuticas y penitenciarias.

Palabras clave: Salud-mental, cárcel, prácticas-profesionales, etnografía

\begin{abstract}
This paper aims to analyze how institutional requirements and emotional assessments impact the daily practice of a civil team that specializes in mental health within a federal maximum security prison in the Argentine Republic. To this end, this paper delves into

Fecha de recepción del artículo: Marzo2020

Fecha de evaluación: Mayo 2020

\footnotetext{
${ }^{1}$ Licenciada y Profesora de Sociología (FSOC-UBA) Magíster en Antropología Social (IDESIDAES/UNSAM), Doctoranda en Ciencias Sociales (FSOC-UBA) "Becaria doctoral en el Centro de Investigaciones Sociales (CIS) del Consejo Nacional de Investigaciones Científicas y Técnicas (CONICET) y del Instituto de Desarrollo Económico y Social (IDES)".

Correo electrónico: mrojasmachado@gmail.com.
} 
the admission stage, where health professionals decide whether to include typified inmates who suffer from a mental condition in their psychiatric devices in order to account for the factors that exceed the disciplinary criteria and define the relationship between psychiatric-therapeutic and penitentiary logics.

Keywords: Mental-health, prison, professional practices, ethnography

\section{Résumé}

Cet article vise à analyser la manière dont les exigences institutionnelles et les évaluations émotionnelles affectent la pratique quotidienne d'une équipe civile spécialisée en santé mentale dans une prison fédérale de sécurité maximale de la République argentine. À ce propos, cet article étudie la phase d'admission, dans laquelle les professionnels de la santé décident d'inclure ou pas les détenus typifiés comme souffrant de troubles mentaux dans leur dispositif de traitement afin de rendre compte des facteurs qui dépassent les critères disciplinaires et qui définissent la relation entre les logiques psychiatriques thérapeutiques et pénitentiaires.

Mots-clés:Santé mentale, prison, pratiques professionnelles, ethnographie

\section{Introducción}

El presente artículo forma parte de una investigación etnográfica abocada al análisis de la atención de la salud mental dentro de un contexto de tutela estatal particular, el pabellón psiquiátrico-penitenciario de una cárcel federal de varones ubicada en la Provincia de Buenos Aires (República Argentina). Su particularidad radica en la presencia simultánea de dos referentes institucionales: el Servicio Penitenciario Federal (SPF) y el Programa Interministerial de Salud Mental Argentino (PRISMA), creado en la órbita de los Ministerios de Salud y Justicia y Derechos Humanos de la Nación con el objetivo de dar cumplimiento con la Ley Nacional de Salud Mental No 26.657 (LNSM) en los contextos penitenciarios federales ${ }^{2}$. El mismo fue emplazado en el Complejo Penitenciario Federal

\footnotetext{
${ }^{2}$ La Ley Nacional de Salud Mental N. 26.657 fue promulgada en el año 2010 y conforma un cambio en el abordaje de la salud mental, consignando su carácter de problemática multideterminada por factores económicos, sociales, culturales, biológicos, psicológicos e incluso históricos (y no simplemente en términos de enfermedad); que identifica al "padeciente mental" como una persona en situación de vulnerabilidad psicosocial, que precisa acciones concretas del Estado. Desde esta perspectiva, toma en
} 
I (CPFI) de la localidad de Ezeiza y se constituyó como una intervención civil al interior del espacio carcelario, encargado del tratamiento de personas privadas de libertad por la aplicación de una "medida de seguridad curativa" regulada en el Artículo 34 del Código Penal, y otros detenidos tipificados con diagnósticos psiquiátricos que requieran atención especializada. Para quienes transitamos sus lúgubres pasillos, fue ineludible escuchar hablar del "desborde" del PRISMA, de la "imposibilidad de atender la salud mental de los pacientes adecuadamente", de "instalar una lógica hospitalaria dentro de un espacio penitenciario". Pese a sostener distintos criterios y sentidos sobre aquello que podía entenderse y esperarse de un tratamiento psicoterapéutico en ese contexto, había una creencia compartida (fueran agentes del SPF o profesionales PRISMA) que ubicaba al perfil de los pacientes que ingresaban al pabellón como un obstáculo para su funcionamiento. Por otro lado, estar inmersos dentro de la estructura del SPF limitaba la capacidad de maniobra de los profesionales de salud y su autoridad para definir criterios de funcionamiento de acuerdo con prioridades clínicas y/o terapéuticas. Los agentes penitenciarios, por su parte, veían desdibujado su accionar y consideraban que su conocimiento y formación no eran debidamente valorados.

La sensación de que el PRISMA vivía al borde del colapso formaba parte de las perspectivas nativas de los actores. Los profesionales civiles asumían que, pese a su intento por admitir únicamente a quienes cumplieran con dichos criterios, en la práctica cotidiana surgían dificultades que relativizaban las fronteras entre los "pacientes que verdaderamente merecen ser incorporados" y los "refugiados" o "caños". Por ello, sostenían que debían estar precavidos sobre quienes aparentaban demandas de tratamiento para evitar la crudeza de la cárcel común. El "refugiado" o el "caño" eran categorías nativas referidas a perfiles violentos, reincidentes que habían sido incorporados al Programa, pero que no cumplían con los requisitos para los cuales éste había sido creado. De acuerdo con mis observaciones, su evocación solía dar sentido a los problemas de funcionamiento que observaban, como una justificación ante la distancia entre las normativas del Programa y lo que habitualmente hacían (o podían hacer) y para expresar en qué medida debían lidiar y negociar con criterios penitenciarios, perfiles de pacientes "difíciles" o de "extrema peligrosidad" (como solían describirlos).

consideración los derechos fundamentales de estas personas y su derecho a recibir intervenciones terapéuticas lo menos invasivas posible. 
Así pues, resultó pertinente indagar quiénes eran estos "refugiados", quiénes eran pacientes legítimos (es decir, aquellos que cumplían con las disposiciones del Programa); bajo qué criterios se clasificaban unos y otros, y como operaban en la prácticas estas clasificaciones.

En estas páginas procuro analizar un aspecto de la implementación de una política social desde su devenir cotidiano, considerando aspectos que surgen del encuentro entre agentes estatales y destinatarios. Concretamente, indago la injerencia de requerimientos institucionales y valoraciones afectivas que exceden los criterios disciplinarios de los profesionales de la salud mental y los objetivos gubernamentales del PRISMA, en relación a la definición de sus destinatarios y de las condiciones que les confieren estatus de pertinencia. A tales fines, describo y analizo la instancia de admisión, en la que los profesionales deciden la incorporación de internos penitenciarios tipificados con algún padecimiento mental dentro de su dispositivo de tratamiento. Interrogo la vinculación entre criterios disciplinarios expertos y la lógica penitenciaria, en la producción y circulación de categorías clasificatorias y en las disposiciones concretas propias de los saberes psiquiátricos y psicoanalíticos. Asimismo, este artículo busca dar cuenta del lugar que ocupan el afecto y la ética en un abordaje hospitalario concreto.

La fundamentación empírica de este trabajo está basada en un trabajo de campo etnográfico (Guber, 2011) realizado en el año 2015 dentro del pabellón psiquiátrico de varones del Complejo Penitenciario Federal I de Ezeiza (Buenos Aires, Argentina) durante seis meses. Como fue mencionado, era una unidad gestionada por profesionales civiles del PRISMA a cargo del tratamiento de la población alojada (conformado por psiquiatras, psicólogos, trabajadores sociales, enfermeros y talleristas) y agentes del SPF de distintos escalafones cuyas funciones estaban exclusivamente pautadas para tareas de seguridad y vigilancia. Mis actividades de campo consistieron en participar de la vida colectiva al interior de la institución, las entrevistas de admisión que realizaba el personal interdisciplinario del Programa, reuniones del equipo profesional del PRISMA, eventos especiales organizados por la institución, talleres culturales y asambleas. Asimismo, recurrí a la revisión de materiales nativos y opté por el desarrollo de entrevistas en profundidad para complementar observaciones. Debo señalar que, al momento de realizar el trabajo de campo, el PRISMA atravesaba un proceso en el que buscaba aumentar su visibilidad, transcendiendo los límites de la institución, facilitando la tarea de quienes 
deseábamos hacer etnografía en un establecimiento de tan difícil acceso. El permiso gestionado concluyó en diciembre del 2015 con el cambio de gobierno inaugurado por la Presidencia de Mauricio Macri. A pesar de que esta situación podría implicar diferencias en el funcionamiento del pabellón en la actualidad, estas páginas buscan ser un aporte al campo de investigaciones sobre espacios poco convencionales al interior de las prisiones. El abordaje teórico-conceptual del objeto bajo estudio requirió de una articulación heterogénea de líneas de indagación y discusiones que problematizan la relación entre salud, enfermedad e institucionalización. Desde la perspectiva del control social, una serie de investigaciones interrogaron la intersección del dispositivo penal y el psiquiátrico enfatizando las lógicas de poder y normalización que operan sobre las personas rotuladas por "el crimen" y "la locura", generando las condiciones para el control y la vigilancia de sus cuerpos, espacios y subjetividades . Estos autores sostuvieron que esta población es clasificada por un saber-poder (Foucault, 2004) encarnado en la psiquiatría forense que determina su enfermedad mental en función de conductas que violan ciertas normas éticas, políticas y sociales (Szasz, 1970). En relación con ello, se produce una medicalización del delito y una patologización del delincuente, en términos de

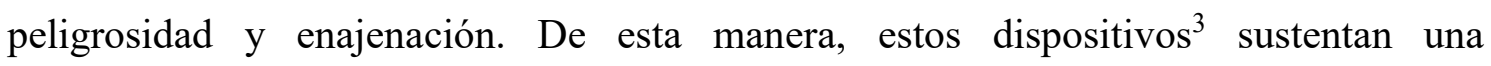
intervención estatal normalizadora de la conducta humana, basada en la peligrosidad como categoría clasificatoria para seleccionar la desviación en función de múltiples respuestas disciplinarias (Foucault, 2010; Pavarini \& Betti, 1999; Pitch, 1999; Sozzo, 1999; Vezzetti, 1985); configurando una identidad híbrida: el loco-delincuente (Sozzo, 1999), sujeto de instancias institucionales específicas capaces de tornarse perpetuas.

La antropología médica y la sociología de la salud aportaron en el análisis sobre el proceso de medicalización en las sociedades modernas occidentales, dando cuenta del proceso de redefinición de problemas que previamente eran clasificados como morales, religiosos o criminales, para ser traducidos en desórdenes del cuerpo o de la mente que debían ser tratados a través de tecnologías terapéuticas específicas (Conrad, 1982; Friedson, 1978; Illich, 1978; Kleinman, 1988, 1995). A partir de entonces, los conocimientos relativos al cuerpo, a la salud y a la enfermedad se posicionan como

\footnotetext{
${ }^{3}$ Por dispositivo entiendo a un conjunto heterogéneo compuesto por discursos, instituciones, decisiones reglamentarias, leyes, medidas administrativas, enunciados científicos, proposiciones filosóficas y morales. El dispositivo es la red que tendemos entre estos elementos, cuya función estratégica dominante siempre está inscrita en una relación de poder y de saber (Foucault, 2002b, 2002a).
} 
entidades construidas social y culturalmente (Epele, 2008; Good, 1994; Grimberg, 2003; Kleinman, 1995; Scheper-Hughes, 1990). Eventos, comportamientos y padecimientos que formaban parte del ciclo de vida de las personas comenzaron a resultar patológicos y plausibles de recibir tratamiento, jerarquizando el poder de los saberes psiquiátricos y psicoanalíticos como parte del mismo proceso (Bonet, 2004; Figueira, 1980; Sy, 2018). En este sentido, la "cultura manicomial" se caracteriza por la psiquiatrización y la psicologización del sufrimiento como sus principales respuestas (Oliveira \& Dorenles, 2005). Dicha dualidad se vincula con el desarrollo de la práctica psiquiátrica en tanto disciplina encargada del control social de las desviaciones.

Como sostiene Mantilla (2010b), el discurso psiquiátrico fue construido históricamente como un dispositivo de poder disciplinario, en tanto práctica productora de un discurso de verdad dentro de la medicina moderna, al que posteriormente se le adhirió el discurso psicoanalítico. En su observación, no se trata de una separación categórica entre estas disciplinas, sino de miradas y abordajes que atraviesan las prácticas de los profesionales sin ser exclusivas de cada una de ellas. En este sentido, recupero para los objetivos de este trabajo la categoría “discursos psi” esbozada por Lorna Rhodes (1996) para hacer referencia a los sistemas culturales que involucran prácticas y saberes psiquiátricos y psicoanalíticos, entendidos desde el reconocimiento de su capacidad para definir, clasificar y dar sentido a las experiencias de las personas. Dentro del contexto de confinamiento psiquiátrico, tales experiencias son transformadas en enfermedades, padecimientos o trastornos mentales, interpelando a los sujetos con padecimientos psíquicos mediante clasificaciones con fuertes contenidos de normalización (Good, 1994; Mantilla, 2008, 2010b).

Estas discusiones asumen otra complejidad cuando se indagan en su vinculación con un contexto penitenciario por la intromisión sus lógicas intrínsecas de funcionamiento, la presencia de estigmas carcelarios, códigos propios a la particularidad del contexto de encierro en el que se encuentran ligados a expresiones de agresividad. Agentes penitenciarios y profesionales civiles solían aludir a la existencia de una "la lógica tumbera" o "cultura de la cárcel". Esta "subcultura del delito", en tanto perspectiva nativa, era un recurso de los actores para explicar prácticas al interior del pabellón, estados emocionales, casos de reincidencia, prácticas y discursos especialmente ligados a la manifestación acciones violentas y conflictos de convivencia entre detenidos. La 
interpretación académica que alude a una cultura específica ligada a la cárcel y al delito (Míguez, 2008; Rhodes, 2004) permitió indagar, documentar y analizar aspectos distintivos de la vida cotidiana en este mundo social. Sin embargo, el enfoque meramente culturalista puede ser proclive a generar una reificación de las relaciones sociales, al tiempo que invisibiliza las continuidades con la cultura convencional y los clivajes dentro del mundo del delito (distanciamiento social entre estas personas, estigmas ligados a tipos de delitos, criterios de legitimidad diferenciada), como señalaron tempranamente Sykes y Matza (2008). En el intersticio de ambos marcos referenciales, aparece la figura del "refugiado" como una categoría nativa que denomina a quienes ingresan al PRISMA sin un criterio clínico legítimo, para escapar de la cárcel común ${ }^{4}$.

La instancia de evaluación que realizaba el PRISMA era un proceso social complejo en el que intervenían condiciones de diversa índole y, al igual que en los ámbitos civiles, implicaba el primer acercamiento en el que se abordaba, interpelaba y clasificaba a los sujetos desde criterios psi. Pese a tratarse de una instancia de admisión que en muchos casos concluía con el traslado de estas personas a otro establecimiento penitenciario, es importante señalar que desde el momento en el que ingresaban al pabellón psiquiátrico de Ezeiza para ser evaluados por el PRISMA, se transformaban en "pacientes". Esto no era únicamente observable en el discurso de los profesionales, sino también en las prácticas de terapia, tratamiento y medicación que recibían durante esos días. Se esperaba de estas personas que colaborasen con las normas y valores del pabellón: que se dispusieran a los espacios terapéuticos, que adoptasen el uso de la palabra como vehículo de comprensión de sus trayectorias, que no se resistieran a la administración de psicofármacos, que "respetasen el tratamiento ajeno", que se despojasen de conductas "tumberas" que traían de sus pabellones de origen (cobro de protección, uso de facas, relaciones de reciprocidad con agentes penitenciarios), entre otras. Para el abordaje del PRISMA, eran "pacientes" antes de que un diagnóstico y un dictamen interdisciplinario así lo disponga. Aunque en primera instancia su identidad está determinada por la ocupación de estos espacios, luego intervenían procesos de mayor complejidad que determinaban y producían a quienes "debían” y "merecían” incorporarse al dispositivo de tratamiento.

\footnotetext{
4Cuando los actores se refieren a "cárcel común" lo hacen en referencia a todos los establecimientos penitenciarios del SPF que se encuentran por fuera del dispositivo de salud mental. Es decir, espacios carcelarios sin la interferencia de agentes estatales civiles.
} 
Ahora bien, desde una perspectiva antropológica fue posible aprehender aspectos menos evidentes en el tratamiento institucional que recaía sobre estas personas, aspectos que diferían de las consideraciones disciplinarias, institucionales o gubernamentales. Concretamente, el registro de las categorías y criterios de decisión que cobraban sentido en un marco de interacción específico: la lógica del vínculo y la lógica de la apariencia. Éstas se producían a partir de una serie de factores que no respondían necesariamente a los discursos y prácticas "psi" en tanto saberes objetivos, sino a un saber situacional que tenía lugar durante las entrevistas, en el que aparecían aspectos vinculados con lo penalpenitenciario. Propongo entonces, abordar estas dimensiones desde el enfoque dramático propuesto por Goffman $(1970,1971,1996)$, en el que los individuos regulan a partir de las apariencias un conjunto heterogéneo de situaciones. El autor sostiene que en el análisis de estas situaciones presenciales se produce un manejo de las impresiones por medio de recursos expresivos que permite situar las prácticas en contextos interaccionales, permitiendo interrogar la relación entre las instituciones y las prácticas. Como sostiene Mantilla $(2008,2010 \mathrm{~b}, 2010 \mathrm{a})$ las impresiones, las apariencias y las miradas que se producen en el encuentro entre pacientes y profesionales construyen el andamiaje de las decisiones terapéuticas. Siguiendo este razonamiento, diversos autores (Strauss, Fagerhaugh, Suczec, \& Weiner, 1997) consideran que el orden institucional no constituye una fuerza exterior que controla a los individuos, sino que los actores en sus diferentes roles (pacientes-internos, profesionales, agentes penitenciarios, etc.) participan activamente de su construcción.

En este trabajo sostengo que, pese a la relevancia de los criterios expertos, todo proceso de admisión está constituido por un conjunto de situaciones interpretativas a las que apelan los profesionales del PRISMA para otorgarles sentido lo que observan y escuchan de sus pacientes, hacer inteligible, explicar y justificar la conducta general de estas personas, y su estado clínico, mental, emocional y penal. Esta situación está condicionada por la ausencia de marcadores biológicos en el campo de la salud mental para su debido diagnostico (Aguiar, 2004; Ortega, 2006). Por lo general, la diagnosis implica la tarea de trasladar comportamientos específicos al lenguaje de la psiquiatría y del psicoanálisis, por medio de la búsqueda de signos capaces de ser patologizados. Razón por la cual, los encuentros clínicos pueden ser interpretados como una relación de negociación entre profesionales y pacientes en las que se ponen en juego el sentido de la enfermedad y del 
tratamiento (DelVecchio Good, Brodwin, Good, \& Kleinman, 1993; Good \& Delvecchio Good, 2000; Mattingly, 1994, 1998, 2000). De acuerdo con esta perspectiva, la medicina construye su objeto a través de narraciones, y sostiene que profesionales y pacientes crean historias mediante sus interacciones cotidianas. Las nociones y operaciones conceptuales propias de los enfoques intervinientes, psiquiátricos y psicológicos, se articulan en una práctica concreta de intervención. El paciente se constituye en objeto de especulaciones teóricas y argumentaciones que explican y organizan su trayectoria institucional en forma de eventos interrelacionados y teóricamente explicados. En el proceso de decisión de admisión, al igual que las internaciones psiquiátricas del ámbito civil, confluyen saberes y prácticas que adquieren significados diferentes para cada uno de los actores involucrados (profesionales y pacientes).

Procuro en este artículo mostrar que el paciente del PRISMA no era un efecto de una disposición meramente institucional, ni podía definirse exclusivamente por las categorías psicopatológicas que le eran asignadas. Por el contrario, formaban parte de un proceso interpretativo en el que también emergían y circulaban estereotipos y categorías propios del ámbito carcelario, afectando las concepciones que los profesionales de la salud mental tenían sobre ellos. Como destinatarios de una política nacional, la inclusión de estas personas dentro del PRISMA estaba definida por medio de un corpus de saberes expertos, presentados a sí mismos en calidad de “objetivos". Sin embargo, durante los meses de trabajo de campo llamó mi atención las constantes objeciones acerca de la pertinencia de admisión de quienes se encontraban alojados en el pabellón psiquiátrico. Indagar este proceso permite acceder a la forma en la que se organiza un conjunto heterogéneo de saberes, disposiciones y lógicas profesionales en el contexto específico bajo estudio.

De modo más amplio, propongo realizar un aporte al estudio de las formas en las que se pone en práctica una política social, entendiendo que éstas constituyen a sus sujetos de intervención a través de una serie de clasificaciones, pero luego los agentes estatales que los ponen en práctica actualizan estas nominaciones en función de trayectorias, identidades, postulados éticos, morales e ideológicos y de contextos o situaciones concretas de implementación. En este último punto resulta fundamental indagar por las relaciones entre estos agentes y los destinatarios del PRISMA en sus instancias de interacción, donde se producían transformaciones en los unos y en los otros. Asimismo, dar cuenta de la permeabilidad de las fronteras disciplinarias, analizando la movilidad de 
clasificaciones psiquiátricas y carcelarias por fuera de los saberes técnicos y profesionales.

En este sentido, el enfoque de este trabajo se diferencia tanto de la perspectiva clásica que considera al Estado como un actor completo, con racionalidad estratégica (Evans, Rueschemeyer, \& Skocpol, 1985; Rueschemeyer \& Skocpol, 1996); como así también de la mirada vinculada a la teoría política que desplaza al Estado del análisis de las políticas públicas para centrarse en otras configuraciones tales como el "espacio público", o en la existencia de distintas formas de legitimidad (Abensour, 1988). El Estado no es entendido como un conjunto de instituciones delimitadas, sino como un sistema de prácticas cotidianas, espacios de encuentro e interacción con otros agentes sociales, y de generación de representaciones culturales.

En otras palabras, se asume una perspectiva que busca evitar la reificación del Estado como entidad monolítica y unificada para ubicar el análisis en las prácticas penales históricamente variables y situadas. Para ello retomo a Lynne Haney (1996, 2002, 2004) en su enfoque sobre el Estado como entidad multidimensional, dispuesto en capas (el diseño institucional, las prácticas de los agentes estatales y la maniobrabilidad de los destinatarios), y compuesto de aparatos que actúan de forma no siempre coherente, homogénea ni unívoca. Asimismo, los aportes de Ernesto Bohoslavsky y Germán Soprano (2010) en su propuesta de "personalizar" y “despersonalizar" el Estado (rescatando las múltiples identidades e intereses en las decisiones estatales, y evitar considerarlo como un agente unívoco con objetivos autónomos, sino como un conjunto de relaciones sociales y personales) y las aproximaciones etnográficas de Jorge Pantaleón (2005), Luisina Perelmiter (2016), que privilegian el análisis de la experiencia y la cotidianidad de la gestión estatal, estudiando el modo en que el Estado es producido y reproducido en prácticas burocráticas "mundanas", en el hacer diario de burócratas y funcionarios, en sus encuentros con los "beneficiarios" o "destinatarios" de las políticas públicas, en las tensiones, adaptaciones y negociaciones que se presentan en ese entramado microsocial, y en las representaciones sociales que circulan por esos contextos particulares de interacción. En otras palabras, procuro situar el foco en el carácter dinámico que adquieren las relaciones al interior de la institución, formas en las que interpretan lo que deben hacer, formas diversas y situacionales de otorgarle sentido, contextos en los que se juegan compromisos, emociones, obligaciones y transgresiones. 
La argumentación se estructura de la siguiente manera: en el primer apartado abordo las características del ámbito bajo estudio, explicitando sus particularidades respecto de otros ámbitos de institucionalización psiquiátrica o penitenciaria. Luego, abordo los criterios disciplinarios establecidos por la normativa del Programa que definen el perfil de quienes pueden ser incorporados al pabellón psiquiátrico. Asimismo, registro los obstáculos que encuentran los profesionales civiles en el abordaje de los padecimientos mentales al interior de una cárcel de máxima seguridad, porque éstos delinean los criterios prácticos posteriormente implementados. En la tercera sección recurro a un conjunto situaciones etnográficas seleccionadas durante el trabajo de campo para analizar instancias concretas en las que se determina la pertinencia de admisión, con el propósito de dar cuenta cómo opera la institución penitenciaria en dichas decisiones, mostrando su incidencia en la construcción de identidades institucionales. Finalmente, reflexiono sobre las limitaciones de los objetivos gubernamentales, dando cuenta de los emergentes que definen la vinculación entre lógicas terapéuticas y penitenciarias en su devenir cotidiano.

\section{EI PRISMA, un acercamiento al objeto de estudio}

Como fue plantado previamente, el Programa Interministerial de Salud Mental Argentino (PRISMA) fue creado por medio de la Resolución Conjunta 1075/2011 y 1128/2011 de los Ministerios de Salud y Justicia y Derechos Humanos de la Nación, con el objetivo de brindar tratamiento especializado a internos penitenciarios tipificados con padecimientos psiquiátricos de distinta índole. El contexto sociopolítico en el tuvo lugar su creación coincidió con el momento en el que el gobierno nacional llevó adelante una serie de medidas para mejorar las condiciones de vida de los internos alojados en instituciones penales (Sozzo, 2015). Al igual que la Sala Psiquiátrica en la U.P. N 1 de Coronda de la Provincia de Santa Fe, existió un proceso de transformación que fue impulsado por el movimiento de salud mental, para luego generar que el ámbito penitenciario incorpore medidas originadas más allá de sus muros (Faraone, 2003; Sozzo, 1999; Valero \& Faraone, 2016) ${ }^{5}$. En este proceso, distintas instituciones penitenciarias buscaron dar

\footnotetext{
5 Debe aclararse que la noción de salud mental utilizada en estas páginas es una terminología institucionalizada con la asistencia de la Organización Mundial de la Salud (OMS), a partir del Instituto Nacional de Salud Mental (INSM) en 1957 (Lakoff, 2005). En efecto, el modelo asilar y la hegemonía médico-psiquiátrica atravesó un proceso de pérdida de legitimidad durante el segundo lustro del siglo XX, evidenciando una amalgama de distintas disciplinas (Galende, 1994; Mantilla, 2008, 2010a). En esta época,
} 
respuesta a la situación de los procesados y condenados que presentasen "alguna de las formas de alienación mental" o "afección mental. Sin embargo, tanto la Procuración Penitenciaria de la Nación (2012), como el Centro de Estudios Legales y Sociales (2013) se esgrimieron sobre la ausencia de consideración dentro de la LNSM de modo particular en las modalidades de abordaje de la salud mental carcelaria.

Antes de la creación del PRISMA y su implementación dentro una cárcel de máxima seguridad, el servicio psiquiátrico de varones se encontraba gestionado por el SPF en la Unidad N²0 del Hospital José T. Borda desde 1979 a cargo de autoridades penitenciarias. El derrotero que concluye con la puesta en funcionamiento del Programa y el traslado a la estructura penitenciaria merece algunas consideraciones. En los primeros años del siglo XXI fueron de público conocimiento prácticas médico-penitenciarias abusivas que implicaron la violación de los derechos humanos de los internos alojados. En el año 2007, la Dirección Nacional del SPF decidió la implementación del Programa Nacional de Atención al Interno con Enfermedad Mental Grave como respuesta ante las denuncias, representando la inserción de un equipo civil de profesionales de la salud pertenecientes al Ministerio de Justicia de la Nación para otorgar tratamiento a la población alojada en la unidad. No obstante, no pudieron desbaratarse el conjunto de prácticas que habían sido denunciadas por organismos de derechos humanos, entre los que se encontraba el Centro de Estudios Legales y Sociales (CELS) y la Mental Disability Rights International (MDRI). Como resultado fue elaborado un informe que denunciaba diversas violaciones a la integridad de las personas detenidas y el incumplimiento del derecho a un trato digno y humano (Mental Disability Rights International \& Centro de Estudios Legales y Sociales, 2007). Años más tarde, en el 2011 se produjo un incendio dentro de una de las celdas de aislamiento de la Unidad N²0 que concluyó con el deceso de dos personas, muertes que se sumaban a los seis internos que habían fallecido durante los meses previos.

\footnotetext{
parte de la psiquiatría argentina recibió la influencia del psicoanálisis para intentar redefinir la modalidad de la atención psiquiátrica. Desde entonces, esta psiquiatría disidente dio lugar al surgimiento del campo de la salud mental en la Argentina (Carpintero \& Vainer, 2004; Galende, 1989; Plotkin, 2003; Vezzetti, 1996; Visacovsky, 2002). De acuerdo con Jonathan Ablard (2003), los objetivos que perseguía esta corriente incluían la integración de la psiquiatría en el campo de la medicina, mejorando los servicios médicos y sociales de los pacientes, modificando la relación entre profesionales de la salud y pacientes, y eliminando la exclusión social de los pacientes. Esta relación problemática entre el poder y la práctica psiquiátrica ha sido abordada en nuestro país por Menéndez (1979) y desarrollada luego por Plotkin (2003) y Visacovsky (2002), quienes discuten interpretaciones lineales señalando la incidencia de estos grupos profesionales en el desarrollo de reformas consideradas "progresistas" desde el punto de vista psiquiátrico, en gobiernos de signo conservador y aún represivo.
} 
Estos acontecimientos aceleraron la concreción de un proyecto que la gestión del Doctor Víctor Hortel en la Dirección Nacional del SPF había estado planificando en relación a sus servicios psiquiátricos: la creación de una "comisión de desguace" que se ocupó de “desafectar el uso penitenciario de los inmuebles del ex Servicio Psiquiátrico Central"; y la mudanza de la unidad al Ala Norte del Hospital Penitenciario Central (HPC) del Complejo Penitenciario Federal I (CPFI) de Ezeiza. En consonancia con ello, se procedió a la creación PRISMA con el objetivo de que las internaciones y externaciones que allí se produjeran fueran realizadas exclusivamente por profesionales de la salud mental, evitando que éstas sean dispuestas por jueces penales (Poblet Machado \& di Marín, 2016) y posicionando a los profesionales penitenciarios bajo la autoridad de este flamante Programa.

Para la atención de las mujeres tipificadas con padecimientos mentales se realizaban traslados de los agentes de salud hacia el Complejo Penitenciario Federal IV (CPFIV) de la misma localidad, en el que cuentan con un espacio diferencial para su atención. Como consecuencia de la mudanza de estas unidades, los servicios psiquiátricos del SPF dejaron de ser parte de la estructura hospitalaria de un neoropsiquiátrico para convertirse en un módulo inserto en un complejo penitenciario de máxima seguridad. Estas medidas implicaron transformaciones en la actividad usual de estos servicios y su puesta en funcionamiento requirió de la implementación de una modalidad articulada de trabajo en la que pudieran llevar adelante la gestión, control y tratamiento de personas detenidas con padecimientos mentales. En el proceso de encuentro entre estos abordajes institucionales, el SPF y el PRISMA, se produjo a un espacio peculiar donde convergieron distintos abordajes disciplinarios, discursos científicos y técnicos, valoraciones afectivas y morales, criterios políticos y ético-profesionales, resultando un ámbito que difícilmente pueda compararse con otros servicios psiquiátricos penitenciarios, sean federales o provinciales (Mouzo \& Rios, 2018; Rojas Machado, 2017).

En el relato de los agentes había una una separación normativa y formal en la que distinguían dos lógicas, la psiquiátrico-terapéutica y la penitenciara, una orientada a la atención de padecimientos psiquiátricos a cargo del personal civil y otra de seguridad que correspondía al personal penitenciario. Como señala Lorna Rhodes (2004) éstas se erigen como dos discursos relacionados, pero a veces en conflicto, dado que uno está centrado en proyectos disciplinarios basados en nociones de racionalidad y el otro en proyectos de 
rehabilitación apuntados a "adquirir una subjetividad normal" (2004: 11). En diferentes instancias de indagación mostramos que la existencia de discursos de funcionamiento que separaban de manera categórica a miembros del PRISMA y el SPF en sus tareas no respondía necesariamente con las dinámicas observadas, sino que se podían advertirse distintos niveles de cooperación y reciprocidad entre las mismas, matizando sus fronteras (Lombraña, 2014; Rojas Machado, 2017, 2018). Por un lado, la creación del Programa supuso modificaciones en la dinámica cotidiana penitenciaria que influyeron en todo un conjunto de prácticas y representaciones, como modificaciones en los protocolos penitenciarios y capacitaciones al personal de la institución. Por el otro, la presencia del personal penitenciario era vista como "necesaria" para los trabajadores civiles, en tanto participasen únicamente cuando emergía una situación que pusiera en peligro la integridad física de alguna persona.

Para su funcionamiento se estipuló la delimitación de las tareas que debía llevar adelante cada uno de los actores institucionales ${ }^{6}$, el PRSIMA y el SPF. Los profesionales civiles tenían a su cargo la evaluación, admisión y tratamiento de las personas alojadas en el pabellón. Contaban con cuerpo de trabajadores conformado por más de sesenta personas: psicólogos, psiquiatras, trabajadores sociales y enfermeros. Cada destinatario tenía un equipo tratante interdisciplinario asignado y podía solicitar asistencia por guardia psiquiátrica de modo permanente. La atención estaba organizada de la siguiente manera: cuando un paciente era admitido, se los trasladaba a una de las dos salas de alojamiento y le era asignado un "equipo tratante" interdisciplinario, al que podía recurrir todas las semanas y cuya demanda solía ser escuchada. "Nosotros tratamos de estar siempre que nos necesiten, eso no lo tenés en ningún lado en las internaciones civiles, un profesional casi a demanda", decía la coordinadora jerarquizando la labor que llevaban a cabo, y enfatizando la diferencia con otros abordajes asilares de la salud mental y con el servicio que anteriormente estaba a cargo de la penitenciaria con padecimientos psiquiátricos. Esta perspectiva era compartida por la mayoría de los trabajadores, quienes posicionaban al PRISMA como un "laboratorio de atención que podía ser replicado aún fuera de las cárceles". Además, la organización de la atención contaba con un área sociocultural a cargo de tres trabajadoras sociales que contemplaba diversas actividades semanales,

\footnotetext{
${ }^{6}$ Utilizo la denominación propia "actores institucionales" para hacer referencia a agentes penitenciarios (en sus distintos escalafones), profesionales y trabajadores de la salud que integran el equipo civil de tratamiento, y autoridades estatales con injerencia directa en la estructura del servicio bajo estudio.
} 
como talleres de cine, revista, coro, emprendimientos socioproductivos, percusión, etc. En ese marco, recibían a personas externas a la institución que llevaban a cabo talleres semanales por medio de contratos de prestación de servicios. Estas personas no formaban parte de la planta de trabajadores del PRISMA, sino que facturan como monotributistas sus horas de trabajo al Ministerio de Justicia y Derechos Humanos.

El SPF contaba con personal administrativo propio y sus funciones involucraban, únicamente, tareas de vigilancia y seguridad: controlaban la circulación de todas las personas dentro del pabellón, los desplazamientos de los pacientes-internos hacia los espacios de trabajo, educación o visita, realizaban las requisas, vigilaban las salas de alojamiento, acompañaban a los profesionales a hacer la ronda de medicación, etc.

Las definiciones sobre las potestades que el SPF y el PRSIMA tenían dentro del pabellón se diluían cuando se las observaba en su actividad cotidiana. La admisión, el tratamiento psicoterapéutico y la seguridad no conformaban entidades independientes y autónomas. Por el contrario, su constante relación daba lugar a situaciones de conflicto entre ellas, evidenciables cuando sucedían episodios de violencia entre pacientes, decisiones de alojamiento que involucraban aspectos clínicos y requerimientos securitarios al mismo tiempo, ausencia de otros dispositivos federales adecuados para internos "conflictivos" con "padecimientos psiquiátricos" que estaban por fuera de los requisitos del Programa, etc.

Por su parte, la población alojada también asumía características particulares que la diferenciaban de los internos penitenciarios y de los pacientes psiquiátricos del ámbito civil. Se distinguían de los primeros porque las calificaciones de conducta y concepto (Decreto N³96/1999, artículo 73) estaban suspendidas para esta población, dejándolos por fuera del sistema de progresividad de las penas, al igual que las visitas conyugales (Ley $\mathrm{N}^{\circ} 24.660$, artículo 68). Por otro lado, pese a recibir un tratamiento psiquiátricoterapéutico intensivo, las dinámicas propias del ámbito penitenciario solían actuar en detrimento de la integridad física y psíquica de la población (Centro de Estudios Legales y Sociales, 2013: 415-416). Por último, debe destacarse que no existía una categoría nativa unánime dentro del pabellón para nombrar a estas personas. Los profesionales solían hablar de "pacientes", los agentes penitenciarios de "internos" o "presos"; y ellos tendían a identificarse con ambas de acuerdo a contextos específicos, y a sus interlocuciones, sean éstas con miembros del PRISMA o del SPF. Por esa razón, utilizaré 
"paciente-interno" para distinguir a quienes se encuentran alojados dentro del pabellón del PRISMA de otros espacios carcelarios.

\section{Los saberes expertos}

Desde la normativa, el propósito del PRISMA era tratar la problemática de salud mental de personas alojadas en los distintos establecimientos del SPF, pero en la práctica este procedimiento podía verse dificultado por múltiples situaciones. En este apartado expongo las características que debía cumplir un interno penitenciario para ser considerado paciente del PRISMA y los condicionamientos externos a los saberes disciplinarios que intervenían en las evaluaciones para comprender qué atributos hacían de un paciente un obstáculo para el tratamiento, y cómo llegaba a ser admitido en el dispositivo.

El equipo interdisciplinario del PRISMA evaluaba sus ingresos por derivación judicial o penitenciaria dentro del Servicio de Evaluación, Diagnóstico y Estabilización (SEDE), ubicado en la planta baja del pabellón psiquiátrico. Se trataba de una oficina que contaba con una celda reducida, un baño y capacidad de alojamiento de hasta tres personas para varones, y una sala más pequeña con dos camas y un baño para mujeres. Ambas habitaciones estaban equipadas con cámaras de vigilancia y monitoreo constante. Quienes ocupaban estas instalaciones no tenían acceso a otras secciones del penal, exceptuando pequeños intervalos de tiempo en los que se les permite acceder al patio. Era habitual escuchar sus quejas debido a que las condiciones de alojamiento y el encierro permanente eran difíciles de tolerar.

La definición formal de los destinatarios del PRISMA incluía a personas privadas de libertad por la aplicación de una "medida de seguridad curativa" regulada en el artículo 34 del Código Penal, trastornos psicóticos agudos y transitorios, elevado riesgo de suicidio, cuadros clasificados como excitación psicomotriz, esquizofrenia y/o trastorno de ideas delirantes persistentes, trastornos mentales severos y "retraso mental moderado, grave y/o profundo". No eran admitidos quienes arribasen por ideación suicida (sin tentativa ni planificación), trastorno de la personalidad, desórdenes vinculados al consumo de sustancias (para los que existían otros dispositivos gestionados 
exclusivamente por el SPF) ${ }^{7}$, y retraso mental leve. Estos criterios se ceñían en la consideración de una sintomatología psiquiátrica sistematizada en cuadros clínicos estandarizados en dos nomencladores internacionales. Por un lado el Clasificación internacional de enfermedades (CIE10), un sistema de codificación de enfermedades y causas de muerte publicada por la Organización Mundial de la Salud (OMS), utilizada principalmente con propósitos estadísticos (1995). En segundo lugar, el Manual diagnóstico y estadístico de los trastornos mentales de la Asociación Americana de Psiquiatría (1994), conocido como el DSM. Se trata de un sistema de clasificación de los padecimientos mentales que proporciona descripciones de las categorías diagnósticas, con el propósito de que pueda estandarizarse su información, estudio y abordaje. Al momento de la investigación, los profesionales utilizaban la cuarta edición de dicho manual. $^{8}$

Los profesionales civiles asumían que pese a su intento por admitir únicamente a quienes cumplieran con dichos criterios, en la práctica surgían dificultades que relativizaban las fronteras entre los "pacientes que verdaderamente tienen una demanda de tratamiento" y los "refugiados" o "caños". Consideraban que permanecer en el pabellón del PRSIMA podía significar una mejora sustantiva de las condiciones de encarcelamiento, especialmente por el control que ejercían sobre el SPF para que respetasen los derechos humanos y la integridad física de los detenidos. Incluso, publicaciones emitidas por miembros del programa (Izaguirre \& Alcoba, 2013) e informes de organizaciones civiles (Centro de Estudios Legales y Sociales, 2013), mencionaron que la presencia de equipos civiles limitaba al personal de seguridad el abanico de estrategias disponibles para imponer mecanismos de castigo por fuera de la ley y de las reglamentaciones que organizan oficialmente la vida intramuros (Daroqui, 2002; Míguez, 2007; Vázquez Acuña, 2007), como prácticas de aislamiento, administración abusiva de medicación psicofarmacológica, maltratos físicos y psicológicos, restricción de acceso a espacios de esparcimiento y/o recreación, entre otros. Por ello, sostenían que debían estar precavidos ante quienes aparentaban demandas de tratamiento para evitar la crudeza de la cárcel común. Consideraban que durante los días de evaluación llevaban a cabo la tarea

\footnotetext{
7 Específicamente, se trata del Programa de Asistencia Grupal para Adictos (AGA), los Centros de Rehabilitación de Drogodependientes (CRD) que se encuentran en distintos establecimientos del SPF en el país, y el Programa de Tratamiento Interdisciplinario, Individualizado e Integral (PROTIN) del CPFI, que usualmente permite el alojamiento de internos con diagnósticos ligados al consumo de sustancias.

${ }^{8}$ Para una diferenciación de sus distintas ediciones consultar Mantilla (2011a: 4-5).
} 
dificultosa de "menguar los prejuicios que tienen muchos pacientes sobre el PRISMA y detectar a quienes buscan beneficios", como decía una de las psicólogas. Su preocupación hizo que crearan una herramienta para "medir y detectar" la simulación en las entrevistas, motivados por la presunción de que era muy común "hacerse pasar por loco para tener mejores condiciones de alojamiento penitenciario, o el acceso a psicofármacos". Esta herramienta recibió el nombre de "Protocolo de Evaluación de Simulación" y fue utilizada por miembros del dispositivo de evaluación durante un breve lapso de tiempo, cuyos fundamentos se encuentran publicados en un artículo en la Revista Neuropsicología, Neuropsiquiatría y Neurociencia (Bertone et al., 2012). Al respecto, uno de los profesionales del programa argumentaba:

El trabajo es bastante complicado porque acá nos llega de todo y tenemos que deliberar si hay una sincera demanda de tratamiento, o si se trata de personas que buscan un mejor contexto penitenciario para el cumplimiento de sus penas. Sabemos que este lugar no es como la cárcel común, es un sitio más seguro, más tranquilo, y muchos están en busca de eso ¡Ni hablar de la posibilidad de acceder a medicación psiquiátrica! (Psicólogo, SEDE, agosto de 2015).

Por otro lado, la presión por realizar diagnósticos adecuados se jerarquizaba con el argumento de dar respuesta adecuada a la demanda genuina de internos penitenciarios al interior del SPF. En el 2015, cuando realicé el trabajo de campo, esta institución albergaba a una población que rondaba las doce mil personas, cuyo $63 \%$ se encontraba dentro del área metropolitana. El pabellón contaba solamente con sesenta plazas, insuficientes para resolver las necesidades de la órbita federal, especialmente considerando a quienes se encontraban alojados en el interior del país ${ }^{9}$. Al respecto, el informe del Centro de Estudios Legales y Sociales del año 2013 manifestó que una de las mayores deficiencias del PRISMA radicaba en su limitado alcance nacional, dejando a las unidades penitenciarias federales del resto del país fuera de su campo de acción. Esto suponía la prescindencia de tratamientos integrales acordes con la normativa en salud mental

\footnotetext{
${ }^{9}$ En la actualidad, la cantidad de personas detenidas aumentó considerablemente, llegando a un nivel de sobrepoblación del 15\%. Esta información fue extraída del sitio oficial del Servicio Penitenciario Federal (https://www.spf.gob.ar/www/estadisticas). Recuperado el 20 de octubre de 2019.
} 
vigente, por lo que insistían en clasificar al PRISMA como un dispositivo de "buenas intenciones", pero con acotada efectividad en sus objetivos (2013: 415).

En cuanto a su funcionamiento operativo, el proceso de admisión tenía lugar durante un plazo mínimo de 72 horas en el que el equipo interdisciplinario realizaba entrevistas con el propósito de confeccionar un diagnóstico sobre el "paciente" y determinar la pertinencia de su incorporación. El procedimiento estaba pautado de esa manera para realizar un seguimiento exhaustivo y adecuado de la evolución de estas personas, evitando tomar decisiones focalizando en episodios mentales transitorios. Afirmaban que estas precauciones estaban destinadas a realizar intervenciones pertinentes dentro del SPF, fueran éstas sociales, familiares o institucionales, evitando "psiquiatrizar" conflictos que pudieran surgir durante el proceso penal o en el cumplimiento de una condena (Bertone et al., 2012: 126). Por lo general, estaban familiarizados con la causa penal antes del primer encuentro por medio del Legajo Personal Único (LPU) ${ }^{10}$, donde aparecía el registro de un conjunto heterogéneo de intervenciones y puntos de vista desde el momento de su detención. Es importante mencionar que, por lo general, las personas a evaluar no provenían del medio libre, era habitual que lo hicieran luego de largas trayectorias en establecimientos penitenciarios, o de extensas estadías en alcaidías y/o comisarías. Las derivaciones (judiciales o penitenciarias) se rechazaban únicamente cuando no se disponían de camas libres en la sala de alojamiento, entendiendo que no podía realizarse un proceso de evaluación si no estaban en condiciones de responder tal demanda.

\section{Viñetas psiquiátricas y carcelarias}

Como fue mencionado, la admisión era un proceso interpretativo de complejidad, en el que los profesionales daban sentido a las observaciones sobre los pacientes y sus relatos. Dentro de un contexto penitenciario, en nuestro caso de máxima seguridad, esta situación adquiría otros matices, condicionamientos y prioridades.

\footnotetext{
${ }^{10}$ Estos LPU, legajos personales únicos forman parte del procedimiento burocrático que abarca una gran variedad de oficinas, funcionarios y recursos estatales -se pone en marcha y cada una de las intervenciones judiciales, terapéuticas y penitenciarias se asientan en alguna foja, ficha, informe o registro que conforman una carpeta denominada legajos personales únicos (LPU) o prontuarios (como son referidos coloquialmente por los funcionarios que los crean y administran). Estos artefactos, cuya construcción es permanente, debe consignar al menos la siguiente información: filiación, situación legal, datos de salud, familiares, educativos, laborales, nómina de las personas autorizadas a la visita y sus antecedentes judiciales y criminológicos (Lombraña \& Ojeda, 2013).
} 
En este apartado pretendo mostrar a través de observaciones y situaciones etnográficas registradas en mis diarios de campo, que en la articulación entre los abordajes penitenciarios y psiquiátrico-terapéuticos, los actores encontraban nociones propias y diferenciales acerca de quienes "merecían" estar en el pabellón del PRISMA, quienes asumían el rol de "refugiados", y quiénes abusaban de la "inocencia y buena intención de los profesionales civiles". Estos recursos no aludían a aspectos formales de la institución, sino que intervenían relaciones de poder, saberes profesionales y técnicos, clasificaciones éticas y afectivas que recaían sobre estos sujetos. Sostengo pues, que los pacientesinternos no pueden ser definidos por criterios normativos del PRISMA, ni agotarse en aspectos psicopatológicos individuales. Por el contrario, formaban parte de procesos de conformación que tenían lugar (principalmente) en el SEDE, pero que lo excedían, incorporando aspectos institucionales de mayor envergadura ${ }^{11}$. Debe aclararse que no pretendo indagar la aplicación de las categorías diagnósticas desde un cuestionamiento de su práctica profesional, sino dar cuenta de los factores exógenos que intervienen en la admisión. A tal fin, serán desarrolladas una serie de situaciones etnográficas en las que se observa la prevalencia de presiones institucionales, criterios penitenciarios, valores morales y afectivos que orientan las decisiones profesionales, o la intervención de estigmas y figuras propias de la "cárcel común" que emergen como condicionamientos. Era un jueves de agosto y yo acababa de llegar al pabellón para participar de uno de los talleres del área sociocultural. Desde el patio se escuchaban gritos y golpes en las puertas, la reja de ingreso estaba con candado de forma permanente y había control penitenciario en todos los accesos con mayor personal de seguridad que en otras oportunidades. Apenas entré, vi a una persona en el salón de usos múltiples (SUM) ${ }^{12}$ gritándole a los agentes que estaban cerca y exigiendo que lo sacasen de ahí. Los pasillos estaban particularmente circulados por agentes penitenciarios y profesionales intercambiando puntos de vista. En ese momento me encontré con una psiquiatra que estaba llegando al pabellón, nos

\footnotetext{
${ }^{11}$ Es importante destacar que el proceso de conformación del paciente-interno en su globalidad excede los objetivos de este trabajo, centrado en las prácticas de los actores institucionales. La participación activa de pacientes-internos dentro de sus contextos de interacción, las salas de alojamiento, es un dato fundamental para comprender de manera integral la producción de identidades en el campo. Para una lectura sobre ello, consultar: Rojas Machado (2017: 101-113).

${ }^{12}$ El salón de usos múltiples (SUM) estaba ubicado en la planta baja. Era el espacio más amplio del que disponía el pabellón psiquiátrico y se utilizaba para recibir a las visitas de los pacientes-internos, talleres y eventos numerosos, y era el ámbito donde se realizaban las muestras de fin de año del área sociocultural, entre sus principales usos.
} 
dirigíamos a la sala de profesionales cuando se acercó la psicóloga encargada del área de evaluación y le dijo:

-Tu chiquito está un poco descontrolado hoy. Te estábamos esperando-

Se lo dijo y se retiró. La psiquiatra se quedó tan irritada que no pudo evitar descargarse conmigo, a pesar de que no teníamos un vínculo estrecho de confianza:

¡Yo esto no lo puedo creer! La gente de evaluación hace cualquier cosa y después espera que nosotros estemos para apagar los incendios. Este paciente está acá desde hace más de una semana, yo dejé claro en muchas oportunidades que no tiene criterio para estar acá. Es obvio que tiene un montón de problemas, pero si vas a los pabellones más duros de la cárcel común son todos como él, todos a esta altura tienen problemas. Es demasiado conflictivo para estar acá, un peligro. Entonces, ellos los admiten y después nosotros tenemos que hacer magia para que no se vaya todo a la mierda. Así no se puede. Hace días que estoy tratando de que tome la medicación. No quiere ser medicado y no quiere hablar... Es imposible darle tratamiento ¿Qué esperan que hagamos con alguien así? ¿Para qué lo vamos a tener acá?

El paciente-interno había sido trasladado al pabellón del PRISMA desde el módulo tres del Complejo por derivación de profesionales del área social del SPF. De acuerdo con los agentes penitenciarios que estaban ese día, se trataba del módulo más peligroso y conflictivo de todo el Complejo. Estuvo varios días en el SEDE, pero tuvo que ser llevado al SUM por problemas de convivencia con otros pacientes-internos que se encontraban en el mismo servicio. Al estar ubicado en el SUM provisoriamente, se suspendieron los talleres que solamente podían llevarse a cabo en ese espacio por la cantidad de participantes. También hubo mayores restricciones de circulación para evitar que se cruzase con otros pacientes-internos. Estas situaciones modificaron el funcionamiento habitual del pabellón, provocando quejas y reclamos del resto de las personas alojadas que sintieron que "por alguien de afuera que no tiene que estar acá, nosotros perdemos las cosas que tenemos".

En la sala de profesionales estaban preocupados por el impacto de esta situación en el tratamiento. A la suspensión de talleres se le adicionaban dificultades espaciales para 
atender debidamente a sus pacientes. Los consultorios estaban en una ubicación de escasa privacidad en la planta baja y cuando se presentaban situaciones conflictivas entre pacientes-internos que modificaban las reglas de circulación cotidianas era difícil sostener el tratamiento. Los agentes penitenciarios, por su parte, tuvieron mayor presencia esos días por la necesidad de incrementar el control y la vigilancia en los pasillos, uno de ellos aprovechó toda ocasión posible para enfatizar que eso pasaba "porque el PRISMA se cree que entiende de la cárcel, pero no sabe nada. Conclusión: nos llenamos de refugiados".

La coordinadora del PRISMA solía destacar que el "perfil tumbero" de los pacientes que llegaban al Programa era un problema porque tenían "la cultura tumbera demasiado internalizada" y esa situación dificultaba la práctica clínica cotidiana, especialmente generando conflictos violentos al interior de las salas. Respecto de los criterios de evaluación, ella destacaba que se manejaban con la mayor rigurosidad posible, respetando la demanda genuina de tratamiento de las personas derivadas y evitando responder a las necesidades de la institución penitenciaria. La mayoría de los profesionales civiles compartió este discurso (la rigurosidad de los criterios y la resistencia a convalidar la necesidad del SPF por encima de las características y necesidades de los pacientes) durante los primeros días del trabajo de campo. No obstante, la permanencia y la observación hicieron posible aprehender otros matices. Recuerdo a uno de los trabajadores sociales del SEDE decirme con preocupación que "últimamente estamos respondiendo más a la demanda de los penitenciarios que a las necesidades de las personas", a una psicóloga reconocer que debieron ser más flexibles con los criterios para evitar el exceso de camas vacías, y otra plantear en una reunión de equipo su frustración al ver "al PRISMA lleno de violines y refugiados ${ }^{13}$."

De acuerdo con el material empírico analizado y en función del objetivo propuesto, consideré que existían tres factores que intervenían en las decisiones de admisión por fuera de los saberes disciplinarios o de las características intrínsecas de los sujetos a evaluar: la necesidad de tener cubierta la capacidad de alojamiento, la compasión ${ }^{14}$ en la

\footnotetext{
${ }^{13}$ Hay una noción extendida, fundada en la permanencia de detenidos sin diagnósticos psiquiátricos precisos, perfiles violentos que perjudican a los pacientes psiquiátricos más vulnerables, especialmente aquellos que poseen discapacidad mental, retrasos cognitivos etc.

${ }^{14}$ La compasión es un concepto fructífero para pensar las relaciones observadas en el trabajo de campo y su abordaje conceptual está vinculado al trabajo de orientación interaccionalista de Candance Clark (1997) sobre las reglas del dar y recibir compasión en los Estados Unidos. Esta investigación está basada en la
} 
respuesta a muestras de sufrimiento por parte de los pacientes y la presión que ejercía el SPF para que incorporasen internos penitenciarios por fuera de sus criterios.

Las camas vacías

La paulatina implementación de la LNSM modificó el perfil de los potenciales pacientes del PRISMA, generando un significativo declive de derivaciones judiciales, en pos de abordajes dentro del ámbito civil. A pesar de que el equipo profesional identificaba a esta situación como un fenómeno reciente, debe mencionarse que en la mudanza de la Unidad No 20 del Hospital José T. Borda en el 2011 representó para muchos detenidos con medida de seguridad curativa la posibilidad de su desplazamiento hacia ese sector (Lombraña, 2014).

Con la reducción de derivaciones de personas declaradas inimputables y la volatilidad de otras que requerían únicamente estabilización psiquiátrica transitoria, la mayor parte de la población del SEDE provenía del interior del SPF. Esta situación generó una flexibilización progresiva de los criterios y el desplazamiento del coordinador del área de evaluación, como me dijo una de las psicólogas:

Antes estaba a cargo José Luis en la coordinación del SEDE y los criterios eran bien distintos, más de la psicología cognitiva, como era la formación que tenía él. Terminaba siendo muy estricto con los diagnósticos y llegamos a tener solamente 35 camas ocupadas. Eso es porque no entendía cómo venía la mano acá. ¡O llenamos todo o nos rajan a la mierda! ¡Esto es así! ¡Es política!

Andrea Lombraña señala (2014: 202-234) que la flexibilidad o rigidez en los criterios de admisión estaba vinculada con la cantidad de población que tenían alojada. Éstos se

noción de reglas de sentimiento para mapear la gramática de la compasión, identificando dos puntos centrales. El primero es la responsabilidad del sujeto por la propia desgracia (si el sujeto es considerado víctima inocente de un sufrimiento que no estaba a su alcance evitar, es digno de recibir compasión. Si, por otro lado, la interpretación de la causalidad del sufrimiento implica la imputación de responsabilidad al que sufre, su derecho a recibir compasión -con todo lo que esto puede acarrear de formas variadas de apoyodisminuye considerablemente). El segundo punto esencial para nuestro análisis es la capacidad micropolítica de la compasión. Para la autora, la compasión competiría para el establecimiento y la reiteración de las formas de la organización social, contribuyendo tanto a reforzar fronteras nosotros-otros como a demarcar relaciones jerárquicas y de poder, inferiorizando a aquel que es objeto de la compasión. 
mantenían en la medida que contaran con la mayor cantidad de plazas cubiertas y cuando esto no sucedía, estaban dispuestos a ser flexibles e incorporar personas por fuera de sus normativas. Para la autora, el PRISMA funcionaba como una herramienta de selección y gestión de la población carcelaria, regulando espacios de alojamiento de la población con padecimiento mental y disponiendo de cierto nivel de influencia sobre los tiempos y los modos de atención de salud mental general en el contexto penitenciario, sugiriendo (ocasionalmente) tratamientos específicos a los profesionales del SPF a cargo de otros dispositivos de atención en salud mental ${ }^{15}$.

Cuando realicé el trabajo de campo, los equipos de evaluación rechazaban una derivación entregando un diagnóstico y una recomendación de tratamiento a sabiendas de que el SPF en reducidas ocasiones tomaba en consideración sus sugerencias. La limitación de espacio para responder a la demanda de tratamientos en la órbita penal federal se presentaba, muchas veces, como el principal argumento para rechazar derivaciones y defender los criterios estrictos que tenían formalmente pautados. El Servicio, por su parte, solía derivar internos que no cumplían con el criterio de admisión, pero consideraban que no podían ser canalizados por ningún dispositivo de atención propio (especialmente en los casos de riesgo de vida por conflictos internos ${ }^{16}$ ). El acercamiento etnográfico, la observación de las entrevistas de admisión y las conversaciones posteriores con el equipo, me permitieron notar que la relación del Programa respecto de la institución penitenciaria guardaba mayor complejidad y que su poder respecto del SPF era relativo. Una mañana uno de los trabajadores sociales, me dijo:

Los juzgados comenzaron en el último tiempo a incorporar la Ley de Salud Mental y ya casi no tenemos inimputables, quedan muy pocos y era el motivo principal de nuestra existencia. En un momento nos dimos cuenta que había más médicos que

\footnotetext{
${ }^{15}$ Como fue mencionado, el Servicio Penitenciario cuenta con dispositivos de tratamiento propios en términos de salud mental. En primer lugar, el Programa de Tratamiento Interdisciplinario, Individualizado e Integral (PROTIN) que funciona en los dos Complejos de Ezeiza (hombres y mujeres). Funciona en los anexos Por otro lado, los grandes complejos del SPF y muchos de sus establecimientos penitenciarios cuentan con programas destinados a la atención de algunas problemáticas de salud mental: Programa de Asistencia Grupal para Adictos (AGA), Programa de Prevención de Suicidios (PPS), Programa para Internos Condenados por Delitos de Agresión Sexual (CAS), el nuevo Programa para Ofensores Sexuales (POS) que funciona en el anexo de la U.9 de Senillosa, y Centros de Rehabilitación de Drogodependientes (CRD).

${ }^{16}$ Nos referimos a aquellas causas penales sumamente estigmatizadas dentro del ámbito carcelario: agresión sexual, femicidio, infanticidio, entre otras.
} 
pacientes...todos nos damos cuenta de eso. Tuvimos que hacer algo y por ahí, entró gente que de otro modo se hubiese derivado a otro lado. Ahora estamos en año electoral sin saber qué va a pasar a nivel nacional, estamos haciendo la plancha, cumpliendo más con la demanda de del Servicio que la demanda de las personas. Algunos dicen que el PRISMA está lleno de refugiados y violines, y la verdad es que tienen razón. Nos dejan acá cualquier cosa. Hace tiempo que somos el aguantadero de la cana por más esfuerzo que hagamos para evitarlo.

La representación del pabellón como un "aguantadero" o un "buzón” del SPF implicaba la identificación de este espacio como el lugar donde los agentes penitenciarios pretendían "depositar todo lo que se querían sacar de encima". Esta noción era compartida por algunos de los profesionales, agentes penitenciarios e, incluso, pacientes-internos. A pesar de los primeros intercambios con el equipo del SEDE, en los que hicieron énfasis en el cumplimiento de sus obligaciones, la fluctuación de la población alojada mostraba ser una variable relevante para analizar las decisiones de admisión y, en consecuencia, cómo se "tumberizaban las salas de alojamiento", aceptando el ingreso (en ocasiones) de internos penitenciarios que no cumplían con los criterios establecidos. Entonces, el caudal de plazas disponibles generaba uno de los principales obstáculos que los actores encontraban en el tratamiento de los padecimientos mentales.

Entonces, la disponibilidad de espacio de alojamiento permitía a los profesionales tomarse algunas licencias respecto de los diagnósticos. Otro de los trabajadores sociales sostenía que para él (siempre que fuera posible) era importante tratar de discernir si se trataba de una persona que pudiera "sobrevivir" en la cárcel común. Su preocupación estaba más centrada en la vulnerabilidad, que en un diagnóstico centrado en el padecimiento mental. Él lo entendía como consecuencia de su formación, una disposición que compartían los trabajadores sociales del dispositivo de evaluación. Por su parte, los psicólogos y psiquiatras reconocían que algunas veces se mostraban propensos a ingresar personas que no cumplían con el criterio pero que por las que "sentían pena", especialmente si requerían pocos días dentro del pabellón.

Compasión y rechazo 
Una mañana llegó Ignacio por derivación de los profesionales de otro establecimiento del SPF por mostrar "signos de depresión y potencial riesgo de suicidio". Entró tímidamente y se sentó frente a nosotros: una psiquiatra, una psicóloga, un trabajador social y yo. Era un joven delgado, morocho y con postura llamativamente encorvada. Apenas se sentó, nos saludó con una tenue sonrisa que delataba años de ausencia de atención médica y odontológica, y algunos efectos que la pasta base tienen sobre las encías y dentaduras. Durante la entrevista, se mostró angustiado, insistió en la constancia de fantasías suicidas, en el enorme sufrimiento que sentía y el deseo de hacerse daño o causarse dolor físico. Más de una vez mostró las heridas de sus muñecas, piernas y antebrazo. Contó con detalle su infancia, el recuerdo de haber pasado hambre, de su madre alcoholizada todas las mañanas, de su padre ausente, de sus hermanos chiquitos con considerables carencias de cuidado. Habló de la necesidad de consumir pasta base para olvidar "al menos por un ratito la miseria de la vida”. Gesticulaba mucho e insistía en mostrar sus marcas, cortes realizados hacía pocos días, sobre otras líneas ya blancas que permanecían en su piel pero que evidenciaban mayor antigüedad.

La forma en la que se expresaba frente al equipo de profesionales era recurrente en el SEDE. Las cicatrices de su cuerpo, las marcas de los cortes que mostraba insistentemente, sus dientes, su extrema delgadez, se exponían como testimonio de relaciones sociales encarnadas, de su contexto socioeconómico, afectivo, de su historia de consumo de sustancias. El equipo de evaluación buscaba signos de padecimiento psiquiátrico y vulnerabilidad en las expresiones corporales de las personas, procurando dilucidar la veracidad del sufrimiento enunciado y la profundidad de sus expresiones de dolor. Los profesionales reconocían que, en estos casos, eran más permeables a modelar los criterios sobre quienes consideraban demasiado débiles para "sobrevivir en la cárcel”, siempre que tuvieran disponibilidad de camas, como sugirió una la psicóloga presente luego de una entrevista:

Este paciente necesita solamente veinte días para salir en libertad, es medio tontito, pero no tiene criterio específico para estar acá. A mí la verdad es que me da mucha pena, es muy débil, tiene mucho miedo y muy pocos recursos simbólicos... lo dejaría acá hasta que salga, lugar por ahora tenemos. 
Este tipo de escena tenía cierta frecuencia en la instancia de admisión, como sostuve en trabajos previos $(2017,2019)$. Por un lado, el recurso por parte de los pacientes-internos de evocar sus cuerpos, mostrar sus marcas, cortes, signos de padecimiento. En términos generales, estas marcas adquieren un estatus particular dentro del ámbito psiquiátricoasilar a pesar de no ser privativas de los mismos, como señalaron Daniel Míguez (2002) y María Epele (2010). Sin embargo, siguiendo con Mantilla, en el caso de las internaciones psiquiátricas "el cuerpo aparece de manera ineludible" (2010a: 119), siendo marcado desde el ingreso en la institución, y constituido como sede del ejercicio de poder y control de los discursos y prácticas psi. Desde que ingresan aguardando el dictamen, los pacientes-internos reciben un tratamiento que, en términos de la autora, es primordialmente corporal: las formas de se les administra la medicación, a veces a través de inyecciones intramusculares, las contenciones físicas, la modificación de hábitos de vestimenta y cuidado personal y el encierro son sólo algunas de las instancias en que el cuerpo es marcado (Mantilla, 2009, 2010a, 2011b). De hecho, señala que algunos pacientes después de un tiempo de internación comienzan a llevar adelante una serie de prácticas como "cortarse" o pedir refuerzos de medicación, que dan cuenta de la incorporación de actitudes y formas de expresión comunes al interior de la institución.

Por otro lado y de mayor relevancia en los objetivos del presente artículo, observé en las entrevistas de admisión los modos en los que los profesionales de la salud buscaban signos de padecimiento y vulnerabilidad en aquellas expresiones corporales. En ese sentido, recupero el concepto de performance de sufrimiento de Didier Fassin (2003) a partir del cual el autor señala que en los últimos decenios se produjo una reconfiguración de la gestión de, lo que él llama, la exclusión y la precariedad, en la que los sentimientos morales penetraron la esfera pública donde el sufrimiento centrado en muestras corporales permite justificar prácticas de asistencia. Los afectos y los valores morales se pliegan en el discurso político contemporáneo, donde los funcionarios movilizan representaciones que definen a los destinatarios de su labor. En el SEDE podía observarse al cuerpo de los pacientes-internos puesto en escena siendo aquella su única herramienta para hacerse valer en el contexto de la admisión. Los profesionales escrutaban esas marcas, las buscaban en el cuerpo y en la expresividad de los pacientes-internos, indagaban sobre el sufrimiento, a veces lo patologizaban, otras veces lo consideraban "impostado", y algunas "insuficiente" para la incorporación en el Programa. Estos 
criterios condicionaban las decisiones de admisión, aparecía una gramática de la compasión, entendida en los términos de Clark (1997) como forma de legitimar o dar sentido al sufrimiento ajeno, como lo ilustra la una psicóloga del SEDE.

En el caso de este paciente yo encuentro que hay una demanda de tratamiento genuina. Desde que llegó estamos realizando entrevistas y notamos que se encuentra en un estado bastante deteriorado, física y cognitivamente. Tiene el cuerpo todo cortado y está medio desnutrido. Todavía tenemos que seguir evaluándolo y la decisión, como sabés, las tomamos en equipo, pero me atrevería a decir que se va a quedar. Está muy deprimido y vulnerable. Tiene mucho sentido que esté acá y va a poder aprovechar bastante el tratamiento.

La apelación al sufrimiento y a la vulnerabilidad aparecía en pos de lo que Fassin denominó una economía moral de la ilegitimidad en la cual, sumisos en relaciones de poder, "el cuerpo aparece como única fuente de derechos (Fassin, 2003). Entonces, eran los profesionales del PRISMA aquellos expertos que legitimaban estas disposiciones y les asignaban (o no) un criterio de veracidad. Por supuesto que esto no supone un juicio de valor sobre su tarea, sino hacer visibles y comprensibles aspectos que formaban parte de la práctica cotidiana en las evaluaciones y del contexto de la toma de sus decisiones. En vinculación con esta situación, el SPF consideraba que los profesionales del PRISMA tenían buenas intenciones pero se dejaban engañar fácilmente por su escaso conocimiento sobre la población penitenciaria. Identificaban problemático el comportamiento "ingenuo e indulgente" de los profesionales, así señalaba uno de los agentes de mayor antigüedad con esta población:

A esta altura todos sabemos que esto debería funcionar como un hospital, pero no se puede la gente que entra. Habrás visto que acá los dejan hacer cualquier cosa, el preso tiene el ego tan alto que cree que está por encima de todos ¿qué pasa? Hay más facas y más conflictos. Vienen los profesionales y les regalan cigarrillos, café y ellos empiezan a creer que tienen más poder, aumenta la agresividad y la violencia. Ellos [en referencia a los profesionales] no son malos, tienen buenas 
intenciones pero no conocen, entonces meten acá a tipos que no están locos, que se aprovechan. Debajo de la mentira hay un gran abuso.

Para los agentes, el pabellón también estaba "lleno de refugiados", personas que acudían al PRISMA para hacer "lo que no pudieron hacer en los pabellones comunes: agredir y violentar a los demás”. En esta percepción, colocaban a los profesionales en el lugar de "ilusos", "ingenuos" y "víctimas de las mentiras de los internos que se hacen los pobrecitos".

Algunas veces, estos casos resultaban polémicos al interior del equipo PRISMA. Los profesionales del dispositivo de tratamiento, a veces sentían que estas licencias que se tomaban en las evaluaciones flexibilizando los criterios de admisión complicaban su trabajo cotidiano, al permitir el ingreso de personas que no cumplían con los requisitos y que eran muy "difíciles de tratar", especialmente teniendo en cuenta las muestras de fragilidad frente a profesionales civiles no estaba exenta de actos de brutalidad al interior de las salas de alojamiento (Rojas Machado, 2019). Al respecto, en una de las reuniones de equipo pude presenciar discusiones sobre los límites de estas adecuaciones, mostrando que (incluso) dentro del equipo de trabajadores de la salud el debate sobre quienes deben ser admitidos no estaba saldado. Como expongo en el próximo apartado, el análisis de la situación en la que se produce la interacción entre profesionales y pacientes dentro de SEDE es fundamental para hacer inteligibles los valores dentro de la institución, en tanto las muestras de sufrimiento, podían ser también interpretadas con desagrado $\mathrm{y}$ desconfianza mostrando la interviniencia de otros aspectos relevantes para la toma de decisiones.

\section{La presión penitenciaria}

La tercera situación que repercutía en la identificación de los pacientes como obstáculo de tratamiento tenía que ver con la percepción de que el SPF ejercía presión sobre las decisiones de admisión. Quienes tenían potestad de derivación, en acuerdo con agentes responsables de la seguridad, solían derivar personas que no eran estrictamente pacientes psiquiátricos, sino delincuentes con causas penales que podían recibir agresiones en pabellones comunes (especialmente las causas vinculadas a femicidios, infanticidios y 
violaciones). Esta situación era percibida por el PRISMA como una amenaza a los objetivos del Programa que transformaba al pabellón en un "buzón”, lleno de "caños" y de "refugiados", como señalaba uno de los psicólogos del equipo.

El problema es que uno viene con cierta lógica terapéutica, ciertas concepciones que son ético-políticas también y tienen mucho que ver con todos los cambios que hubo en la salud mental, pero llegás a una cárcel y todos los parámetros que tenías se van trastocando mucho. Los pacientes a veces son más tumberos que otra cosa, tenemos que estar con personas que por ahí no tienen criterio y te traen problemas en las salas con los que sí. El Servicio presiona para meter acá gente que no debería. Con la gestión de Hotel esto no pasaba tanto, nosotros teníamos más poder de decisión.

Una mañana encontré algo de revuelo cuando entré al SEDE a saludar. "Estamos por hacer una evaluación ¿Te quedás a observar?” me pregunto uno de los trabajadores sociales. Agradecí la invitación, busqué una silla y me senté junto a ellos esperando que los agentes penitenciarios fueran a la celda a buscar a la persona y la acompañen hasta el escritorio. “¿A que no sabés quién es éste?” me comentó la psiquiatra en voz muy baja, “es el loco de caballito”. Un mes antes se había hecho conocido el caso de un hombre que degolló y apuñaló a una mujer que había sido su novia en la adolescencia frente a más de 100 testigos en el barrio porteño de Caballito. Luego, intentó suicidarse, generándose heridas de gravedad. Uno de los tantos casos de femicidio que aparecen en los medios de comunicación. El agresor estuvo internado en un hospital público hasta que le dieron el alta con el traslado a una dependencia penitenciaria. El juzgado determinó que fuera directamente al pabellón psiquiátrico de Ezeiza para su respectiva evaluación.

A la brevedad apareció el paciente en la pequeña oficina del SEDE, un hombre alto, flaco y bastante desmejorado. Se sentó frente a nosotros con los ojos vidriosos por el llanto. Ante las preguntas de los profesionales respondía con evasivas y con frases confusas hasta que finalmente reconoció saber que estaba en una cárcel, y tener bastante miedo sobre su futuro. Pidió un aumento de la medicación para dormir todo el día y no pensar, solicitud a la que los profesionales no accedieron aludiendo razones clínicas. Cuando le consultaron sobre su propia causa penal se agarró la cabeza, empezó a llorar, dijo no 
acordarse de nada, apenas saber dónde estaba. Ante el relato de lo que decía su expediente, el paciente respondió "mi abogada dice que soy inimputable".

La entrevista continuó con respuestas confusas y contradictorias (aún las que versaban sobre temas exógenos a la causa, como su profesión, vivienda o núcleo familiar). Hubo momentos de tensión, especialmente para las mujeres presentes, cuando se acercaba hacia donde estábamos para mostrarnos (con mucha insistencia) unas marcas que decía tener en la ingle cerca de sus genitales y la cicatriz en el pecho que unía sus axilas, aquella por la que casi muere en el intento de suicidio que sucedió el apuñalamiento de aquella mujer, novia de su adolescencia a quien, según dijo esa mañana, "amaba con locura". Cuando se reintegró a la celda, se produjo una extensa conversación sobre contenido que se volcaría en el primer informe. Los y las profesionales estaban de acuerdo en que el paciente simulaba un cuadro de emoción violenta para solicitar la declaración de su inimputabilidad, y que no tenía criterio clínico para ser ingresado en el dispositivo. Sin embargo, decidieron evaluarlo durante unos días más para descartar riesgo de suicidio .

En una instancia posterior lo note más desmejorado, los ojos irritados y con nuevas heridas en los brazos. Continuaba afirmando no recordar nada. Una de las psiquiatras fue incisiva sobre el arma que llevaba consigo "Si estabas llevando un arma, en este caso un cuchillo, era porque potencialmente tenías pensado hacer algo malo, no es común andar con un cuchillo por ahí. No hay que naturalizar la violencia”. El se agarraba la cabeza, lloraba y pedía ser reincorporado. Apenas se fue, la trabajadora social que estaba ese día aseguró que se trababa del "típico caso que el Servicio se quiere sacar de encima, como los femicidas generan mucho revuelo en la cárcel común, lo mandan acá y nos tenemos que ocupar nosotros".

El paciente-interno estuvo durante varios días en instancia de admisión. Los profesionales estuvieron convencidos de que se trataba de un caso de simulación y tenían intenciones de solicitar al SPF su traslado a otra dependencia penitenciaria. En las conversaciones posteriores para la redacción de los informes aparecían expresiones que preponderaban sobre los saberes profesionales: "no tiene sentimiento de culpa", "es un hijo de puta", "quiere zafar de su causa fingiendo locura", "se nota que es un violento". Pese a sostener un discurso sobre la irrelevancia de las causas penales en su trabajo, pude notar su influencia en la elasticidad y rigidez en las admisiones. Cuando se trataba de casos mediáticos o causas de mayor sensibilidad (femicidio, violación, infanticidio etc.), se 
mostraban más inclementes y exponían una mayor desconfianza respecto del discurso y expresividad del paciente. En estos casos, las muestras de sufrimiento y daño corporal resultaban insuficientes y no generaban compasión alguna, mostrando una predisposición que, incluso, tomaba en consideración las expresiones que utilizarían en los informes para evitar favorecerlos en sus causas. Aunque se tratase de personas vulnerables dentro del contexto penitenciario por el estigma que producía la carátula del delito, y que pudieran tener dificultades para sobrevivir en la cárcel, se inclinaban por una mayor rigidez en el diagnóstico y los criterios de admisión. Eso se reflejaba en la predisposición que tenían durante las evaluaciones, la búsqueda constante del remordimiento, y la imputación moral siempre presente: "no puedo creer que no tenga arrepentimiento ni conexión emocional con lo que hizo". El delito, la causa penal, intervenía en el contexto de la admisión.

A pesar de sus intenciones de derivación, el PRISMA debió lidiar con el hecho de estar inserto dentro de la estructura penitenciaria, que generaba condicionamientos en función de sus necesidades, colisionando los propósitos del programa y su autonomía en las decisiones de admisión. Específicamente, cierta coacción para admitir pacientes por fuera de sus dictámenes, especialmente en casos de femicidio y violaciones. Incluso, debieron aceptar por varios días la presencia de un detenido sin criterio clínico que demandó al SPF por torturas, y que corría riesgo de vida en otros establecimientos del organismo. En ese caso, la presión no provino únicamente del Servicio, sino que estuvo acompañada de otras instituciones públicas y civiles de derechos humanos: como el Centro de Asistencia a Víctimas de Violaciones de Derechos Humanos "Dr. Fernando Ulloa", Centro de Estudios Legales y Sociales (CELS), Procuración Penitenciaria de la Nación (PPN), entre otros.

Es importante destacar que la relación entre el PRISMA y el SPF se encontraba vinculada a cambios y decisiones políticas de mayor envergadura que repercutían sobre los resultados de las instancias de admisión. El cambio de gestión de la Dirección Nacional del Servicio Penitenciario en el año 2013, con la renuncia del Dr. Víctor Hortel y su reemplazo por el Dr. Alejandro Marambio, fue fundamental para comprender un viraje en las relaciones de fuerza que colocaron al Programa civil en una relación de mayor subordinación y pérdida paulatina de poder de decisión y negociación frente al Servicio. 
Debe recordarse que Hortel estuvo a cargo de la Dirección entre los años 2011 y el $2013^{17}$. Por eso sostengo que en función de requerimientos políticos también se redefinían lógicas de funcionamiento del pabellón psiquiátrico, haciendo evidente que la porosidad de las instituciones totales (Das \& Poole, 2004; Ferreccio, 2015), y su permeabilidad con procesos políticos de mayor amplitud que repercutían en las prácticas profesionales.

\section{Consideraciones finales}

En estas páginas abordé la injerencia de factores ajenos a las disposiciones gubernamentales del PRISMA y a los criterios expertos de sus profesionales en las decisiones de admisión tomadas al interior del pabellón psiquiátrico del CPFI de Ezeiza para mostrar las situaciones que se producían en el encuentro cotidiano entre agentes estatales y destinatarios. La pertinencia de requerimientos institucionales ligados a la cantidad de plazas cubiertas, los sentimientos de compasión y/o rechazo y la presión del SPF aparecían como factores intervinientes que jerarquizaban las decisiones y les otorgaban distintos sentidos. Los profesionales del PRISMA, en tanto equipo de trabajo dentro de una cárcel de máxima seguridad, definía un conjunto vasto de tácticas (de Certeau, 1994) para producir espacios autónomos donde privilegiasen los abordajes terapéuticos, por fuera del paradigma de la seguridad. Sin embargo, la impronta hospitalaria era permanentemente permeada por las prácticas penitenciarias.

En estas páginas consigné que los pacientes-internos estaban definidos por medio de saberes expertos, pero en el flujo cotidiano eran afectados por requerimientos propios de

\footnotetext{
${ }^{17}$ La gestión del Dr. Víctor Hotel representó un cambio en el abordaje de la cuestión penitenciaria, generando un punto de inflexión en la política implementada. En dos años ordenó que los abogados contratados por el SPF no interviniesen en la defensa de penitenciarios acusados por torturas y malos tratos (evidenciando que la institución ya no ampararía la tortura), dispuso que los presos por delitos de lesa humanidad fueran trasladados a pabellones de presos comunes (perdiendo así los beneficios y generando un enorme conflicto al interior del Servicio), abrió mesas de diálogo con familiares de detenidos y organismos de la sociedad civil con el propósito de modificar los protocolos institucionales respetando los DDHH, habilitó la formación de un sindicato de presos, el Sindicato Único de Trabajadores Privados de Libertad Ambulatoria (SUTPLA) bajo la CTA de Hugo Yasky, retomó el Centro Universitario de Devoto a su pabellón de origen luego de que fuera intervenido y diezmado a partir de una investigación judicial durante la gestión anterior, aumentó las plazas laborales y educativas, entre otras. Con la "fuga" de trece detenidos del Complejo Penitenciario de Ezeiza, debió presentar la renuncia y fue sucedido por Marambio (también civil), un ex Director que se vio forzado a dejar el cargo en el 2011 por graves denuncias de torturas y malos tratos (Procuración Penitenciaria de la Nación, 2009, 2010). Al momento del estudio, el Dr. Emiliano Blanco estaba a cargo de la Dirección Nacional. Las dos últimas gestiones representaron el retorno a las habituales prácticas penitenciarias y un paulatino repliegue de las medidas de promoción cultural, social y educativa.
} 
la institución penitenciaria. Las situaciones etnográficas desarrolladas dieron cuenta de su inserción dentro de la tensión entre los abordajes penitenciarios y psiquiátricoterapéuticos. A pesar de que la asignación de responsabilidades que definen al equipo civil como el decisor de los pacientes alojados, se observó como la lógica de esta institución penitenciaria permea estos criterios, orientando la práctica clínica.

Por otro lado, las interpretaciones de los profesionales eran intentos de traducir al lenguaje psicopatológico los acontecimientos que formaban parte de los sufrimientos cotidianos de sus pacientes, a los que se veían obligados a dar respuestas. La lógica de la apariencia y del vínculo en las entrevistas era características de la interacción social que enmarcan las decisiones de internación.

La demanda del SPF ante la dificultad de alojar algunos perfiles de detenidos, la escasez de dispositivos penitenciarios para asistir demandas generales de salud mental, la relación específica que genera el cuerpo de profesionales con el paciente a evaluar en términos de compasión o rechazo; daban lugar al escenario cotidiano donde se determinaba la decisión de admisión. Los valores y las moralidades operaban como organizadores de criterios “psi”, permitiendo que las clasificaciones psiquiátricas y delictivas se plieguen en la evaluación, evidenciando las tensiones que se producen en el cuerpo civil al estar inserto en la estructura penitenciaria. El paciente-interno del PRISMA se producía en relación con el Servicio Penitenciario, y con los imaginarios morales que se movilizan sobre la "delincuencia". El "refugiado" aparecía en el discurso de profesionales civiles como el principal obstáculo con el que debían lidiar. Asimismo, daba cuenta de que el pacienteinterno no estaba definido por características inherentes e individuales vinculadas a criterios biomédicos, sino a un proceso dinámico y situacional que sucedía al interior de la institución.

Las opiniones divergentes entre miembros del PRISMA y SPF, sumados a los condicionamientos coyunturales relevados que intervenían en las decisiones, daban sentido a uno de los aspectos que limitaban y condicionaban el tratamiento que podían proveer. En estas definiciones se observaban distintos sentidos sobre las implicancias de atender la salud mental dentro de una cárcel y, asimismo, sobre las concepciones profesionales acerca de quienes "merecen" acceder al tratamiento brindado por el Programa.

\section{Bibliografía}


ABENSOUR, M. (1988): La democracia contra el Estado. Buenos Aires: Colihue.

ABLARD, J. D. (2003): Authoritarianism, Democracy and Psychiatric Reform in Argentina, 1943-83. History of Psychiatry, 14(3), 361-376. https://doi.org/10.1177/0957154X030143006

AGUIAR, A. (2004): A psiquiatria no diva. Entre as ciências da vida e a medicalização da existência. Río de Janeiro: Relume Dumará.

AMERICAN PSYCHIATRIC ASSOCIATION (1994): DSM-IV: Diagnostic and Statistical Manual of Mental Disorders (Edición: 4th). Washington, DC: American Psychiatric Association.

BERTONE, M. S., LUGO, M. E. O., VALLEJOS, M., MUNIELlO, J., LÓPEZ, P. L., \& COROMINAS, A. I. (2012): Detección de la Simulación de Enfermedad Mental dentro del ámbito penitenciario mediante el Protocolo de Evaluación de Simulación (PES). Revista Neuropsicología, Neuropsiquiatría y Neurociencias, 12(2), 1-26.

BOHOSLAVSKY, E., \& SOPRANO, G. (2010): Un Estado con rostro humano. Funcionarios e instituciones estables en Argentina (desde 1880 hasta la actualidad). Buenos Aires: Prometeo Libros.

BONET, O. (2004): Saber e Sentir: Uma etnografia da aprendizagem da biomedicina. Río de Janeiro: Fiocruz.

CARPINTERO, E., \& VAINER, A. (2004): Las huellas de la memoria: Psicoanálisis y salud mental en la Argentina de los '60 y '70, 1957-1983. Capital Federal: Topía.

CENTRO DE ESTUDIOS LEGALES Y SOCIALES (2013): Derechos humanos en Argentina: Informe 2013. Buenos Aires: Siglo Veintiuno Editores.

CLARK, C. (1997): Misery and Company: Sympathy in Everyday Life. Chicago, IL, US: University of Chicago Press.

CONRAD, P. (1982): Sobre la medicalización de la anormalidad y el control social. En Psiquiatría Crítica. La política de la salud mental. Barcelona: Crítica Edit.

DAROQUI, A. (2002): La cárcel del presente, su 'sentido' como práctica de secuestro institucional. En G. Kessler \& S. Gayol, Violencias, secuestros y justicias en la Argentina (pp. 169-191). Buenos Aires: Manantial.

DAS, V., \& POOLE, D. (2004): Anthropology in the Margins of the State (first edition). Santa Fe, N.M. : Oxford England: School for Advanced Research Press.

DE CERTEAU, M. (1994): La invención de lo cotidiano. México: Universidad 
Iberoamericana.

DELVECCHIO GOOD, M.-J., BRODWIN, P., GOOD, B., \& KLEINMAN, A. (1993):

Pain as Human Experience: An Anthropological Perspective. Contemporary Sociology, 22(4), 609. https://doi.org/10.2307/2074460

EPELE, M. (2008): Privatizando el cuidado: Desigualdad, intimidad y uso de drogas en el gran Buenos Aires, Argentina. Antípoda. Revista de Antropología y Arqueología, (6), 293-312.

EPELE, M. (2010): Sujetar por la herida: Una etnografía sobre drogas, pobreza y salud (1a ed). Buenos Aires: Paidós.

EVANS, P., RUESCHEMEYER, D., \& SKOCPOL, T. (1985): Bringing the State Back In. Journal of Peace Research, 25(2), 201-201. https://doi.org/10.1177/002234338802500211

Faraone, S. (2003): La desinstitucionalización: Un modelo alternativo para los abordajes en salud mental o una política de reducción económica-administrativa (Universidad de Buenos Aires. Instituto de Investigaciones en Salud Publica). Recuperado de http://bases.bireme.br/cgi-

bin/wxislind.exe/iah/online/?IsisScript=iah/iah.xis\&src=google\&base=LILACS\&lang= p\&nextAction=lnk\&exprSearch=591702\&indexSearch=ID

FASSIN, D. (2003): Gobernar por los cuerpos, políticas de reconocimiento hacia los pobres y los inmigrantes en Francia. Cuadernos de antropología social, 0(17), 49-68. https://doi.org/10.34096/cas.i17.4599

FERRECCIO, V. (2015): Familiares de detenidos: Exploraciones en torno a prácticas de equilibrio institucional en prisiones de Santa Fe, Argentina. Espacio Abierto, 24(1), 113 143.

FIGUEIRA, S. (1980): Psicanálise e Ciências Sociais. Río de Janeiro: Francisco Alves. FOUCAULT, M. (2002a): Historia de la sexualidad 1. La voluntad del saber. Buenos Aires: Siglo Veintiuno.

FOUCAULT, M. (2002b): Vigilar y castigar: Nacimiento de la prisión. Buenos Aires: Siglo Veintiuno.

FOUCAULT, M. (2004): La arqueología del saber. Buenos Aires: Siglo XXI Editores. FOUCAULT, M. (2010): Los anormales. Argentina, Buenos Aires: Fondo de Cultura Económica. 
FRIEDSON, E. (1978): La profesión médica. Barcelona: Península.

GALENDE, E. (1989): Algo para recordar: Lanús y la Salud mental. Buenos Aires: Mimeo.

GALENDE, E. (1994): Psicoanálisis y salud mental. Buenos Aires: Paidos.

GOFFMAN, E. (1970): Sobre el trabajo de la cara. Análisis de los elementos rituales de la interacción social. En Ritual de interacción (pp. 13-47). Buenos Aires: Tiempo Contemporáneo.

GOFFMAN, E. (1971): La presentación de la persona en la vida cotidiana. Buenos Aires: Amorrortu.

GOFFMAN, E. (1996): Frame analysis. Los marcos de la experiencia. Madrid: Centro de Investigaciones Sociológicas.

GOOD, B. (1994): Medicine, rationality, and experience: An anthropological perspective. Cambridge ; New York: Cambridge University Press.

GOOD, B., \& DELVECCHIO GOOD, M. (2000): Two "Fiction" and "Historicity" in Doctors' Stories. En C. Mattingly \& L. Garro (Eds.), Narrative and the cultural construction of illness and healing (pp. 50-69). Berkeley: University of California Press. GRIMBERG, M. (2003). Narrativas del cuerpo. Experiencia cotidiana y género en personas que viven con VIH. Cuadernos de Antropología Social, (17), 79-99.

GRUPO DE ESTUDIOS SOBRE SISTEMA PENAL Y DERECHOS HUMANOS (GESPYDH), PROCURACIÓN PENITENCIARIA DE LA NACIÓN(PPN), \& COMISIÓN PROVINCIAL DE LA MEMORIA/COMITÉ CONTRA LA TORTURA (CCT/CPM) (2012): Registro nacional de casos de tortura y/o malos tratos. Informe Anual 2012. Recuperado de http://biblioteca.clacso.edu.ar/Argentina/iigguba/20161116115535/Informetortura12.pdf

GUBER, R. (2011): La Etnografía. Método, campo y reflexividad. Buenos Aires: Siglo Veintiuno.

HANEY, L. (1996): Homeboys, Babies, Men in Suits: The State and the Reproduction of Male Dominance. American Sociological Review, 61(5), 759-778. https://doi.org/10.2307/2096452

HANEY, L. (2002): Inventing the needy: Gender and the politics of welfare in Hungary. Berkeley: University of California Press.

HANEY, L. (2004): Introduction: Gender, Welfare, and States of Punishment. Social 
Politics: International Studies in Gender, State \& Society, 11(3), 333-362. https://doi.org/10.1093/sp/jxh040

ILLICH, I. (1978): Némesis Médica. La expropiación de la salud. México D.F.: Editorial Joaquín Mortiz.

IZAGUIRRE, A., \& ALCOBA, M. V. (2013): Implicancias de la ausencia de sanciones en las unidades psiquiátricas del SPF. En A. Alagia, J. De Luca, \& A. Slokar, Derecho Penal $N^{\circ} 5$. Delito, culpabilidad y locura. Recuperado de http://www.bibliotecadigital.gob.ar/items/show/1474

KLEINMAN, A. (1988): The illness narratives. Suffering, healing, and the human condition. Nueva York: Basic Books.

KLEINMAN, A. (1995): Writing at the Margin: Discourse Between Anthropology and Medicine (Edición: New Ed). Berkeley (u.a.): University of California Press.

LAKOFF, A. (2005): Pharmaceutical reason: Knowledge and value in global psychiatry. Cambridge, UK ; New York: Cambridge University Press.

LOMBRAÑA, A. (2014): Dispositivos penales de perdón: Modos de decir y hacer en torno a la emoción y el castigo (Tesis doctoral, Facultad de Filosofía y Letras. Universidad de Buenos Aires). Recuperado de http://repositorio.filo.uba.ar/jspui/bitstream/filodigital/2955/1/uba_ffyl_t_2015_903121. pdf

LOMBRAÑA, A., \& OJEDA, N. (2013): Los Legajos Personales Únicos como campo de indagación antropológico. Un ejercicio metodológico. Nuevas tendencias en antropología, 4, 1-24.

MANTILLA, J. (2008): Prácticas y discursos “psi” en torno a las internaciones (Tesis de Maestría no publicada). Facultad de Ciencias Sociales. Universidad de Buenos Aires, Ciudad Autónoma de Buenos Aires.

MANTILLA, J. (2009): Cuerpo y relaciones terapéuticas: Una reflexión antropológica sobre la noción del "trastorno límite de la personalidad”. RBSE, 8(23), 292-342.

MANTILlA, J. (2010a): De persona a paciente: Las prácticas y los saberes psiquiátricos y psicoanalíticos en un hospital de la ciudad de Buenos Aires (Tesis doctoral no publicada). Facultad de Ciencias Sociales. Universidad de Buenos Aires, Ciudad Autónoma de Buenos Aires.

MANTILLA, J. (2010b): La construcción de las decisiones de internación psiquiátrica: 
Un análisis de los argumentos psicoanalíticos y los contextos de interacción social. Intersecciones en Antropología, 11, 145-157.

MANTILLA, J. (2011a): La construcción del diagnóstico psiquiátrico: Un análisis de los saberes y prácticas en juego en un hospital de la Ciudad de Buenos Aires. Ea Journal, 2(3), 29.

MANTILLA, J. (2011b): Manejo y expresión del cuerpo en el caso del trastorno límite de la personalidad: El cuerpo como objeto de prácticas psiquiátricas. Revista Latinoamericana de Estudios sobre Cuerpos, Emociones y Sociedad, 6(3), 20-32.

MATTINGLY, C. (1994): The concept of therapeutic 'emplotment'. Social Science \& Medicine, 38(6), 811-822. https://doi.org/10.1016/0277-9536(94)90153-8

MATTINGLY, C. (1998): Healing Dramas and Clinical Plots: The Narrative Structure of Experience (1 edition). Cambridge, UK ; New York, NY, USA: Cambridge University Press.

MATTINGLY, C. (2000): Emergent narratives. En C. Mattingly \& L. Garro (Eds.), Narrative and the cultural construction of illness and healing (pp. 50-69). Berkeley: University of California Press.

MENÉNDEZ, E. (1979): Cura y control, La apropiación de lo social por la práctica psiquiátrica. México: Nueva Imagen.

MENTAL DISABILITY RIGHTS INTERNATIONAL, \& CENTRO DE ESTUDIOS LEGALES Y SOCIALES: (2007): Vidas arrasadas: La segregación de las personas en los asilos psiquiátricos argentinos: un informe sobre derechos humanos y salud mental en Argentina. Buenos Aires: Siglo Veintiuno Editores.

MÍGUEZ, D. (2002): Inscripta en la Piel y en el Alma: Cuerpo e Identidad en Profesionales, Pentecostales y Jóvenes Delincuentes. Religiâo e Sociedade, 22(1), 21-56. MÍGUEZ, D. (2007): Reciprocidad y poder en el sistema penal argentino. Del 'pitufeo' al motín de Sierra Chica. En D. Míguez \& A. R. Isla, Heridas Urbanas. Violencia delictiva y transformaciones sociales en los noventa. Buenos Aires: Editorial de las Ciencias.

MÍGUEZ, D. (2008): Delito y cultura: Los códigos de la ilegalidad en la juventud marginal urbana (1. ed). Buenos Aires: Editorial Biblos.

MOUZO, K., \& RIOS, A. L. (2018): Programas de atención psiquiátrica y gobierno del espacio carcelario en el Servicio Penitenciario Federal Argentino. Cuadernos de la 
Facultad de Humanidades y Ciencias Sociales. Universidad Nacional de Jujuy, O(53), 13-37.

OLIVEIRA, W., \& DORENLES, P. (2005): Patrimônio e ambiente da loucura: A formação do profissional de saúde mental e o diálogo com a vida da cidade. En P. Amarante, Archivos de Saúde Mental e Atenção Psicosocial 2 (pp. 13-44). Rio de Janeiro: Nau.

ORTEGA, F. (2006): O corpo transparente: Visualização médica e cultura popular no século XX. Historia, Ciências, Saúde, 13, 89-107.

PANTALEÓN, J. (2005): Entre la Carta y el Formulario. Buenos Aires: Antropofagia/Instituto de Desarrollo Económico y Social, (IDES).

PAVARINI, M., \& BETTI, M. (1999): La tutela social de la / a la locura. Notas teóricas sobre la ciencia y la práctica psiquiátricas frente a las nuevas estrategias de control social. Delito y Sociedad, 1(13), 93-110. https://doi.org/10.14409/dys.v1i13.5823

PERELMITER, L. (2016): Burocracia Plebeya. Una etnografia de la asistencia social/La vida íntima del Ministerio de Desarrollo Social. San Martín, Provincia de Buenos Aires: UNSAM Edita.

PITCH, T. (1999): Responsabilidad penal y enfermedad mental. Justicia penal y psiquiatría reformada en Italia. Delito y Sociedad, 1(13), 111-138. https://doi.org/10.14409/dys.v1i13.5824

PLOTKIN, M. B. (2003): Freud en las pampas: Orígenes y desarrollo de una cultura psicoanalítica en la Argentina (1910-1983). Sudamericana.

POBLET MACHADO, M., \& DI MARÍN, E. (2016): Salud Mental, Sistema Penitenciario Federal y Programa Interministerial de Salud Mental Argentino. Tensiones e intervenciones en Problemáticas Sociales Complejas. Revista Margen, 82, 1-6.

PROCURACIÓN PENITENCIARIA DE LA NACIÓN. (2009): Cuerpos castigados: Malos tratos y tortura física en cárceles federales. Buenos Aires: Editores del Puerto.

PROCURACIÓN PENITENCIARIA DE LA NACIÓN. (2010): Informe anual 2010. Recuperado de Poder Judicial de la Nación website: http://public.diariojudicial.com/documentos/000/024/071/000024071.pdf

RHODES, L. (1996): Studying Biomedicine as a Cultural System. En C. Sargent \& T. Johnson (Eds.), Medical anthropology: Contemporary theory and method (Rev. ed). Westport, Conn: Praeger. 
RHODES, L. (2004): Total confinement: Madness and reason in the maximum security prison. Berkeley, Calif: University of California Press.

ROJAS MACHADO, M. (2017): Los dilemas de vivir juntos. Un estudio etnográfico en un pabellón psiquiátrico dentro de una cárcel federal de la Provincia de Buenos Aires (Tesis de Maestría no publicada). Instituto de Desarrollo Económico y Social (IDES)/Instituto de Altos Estudios Sociales (IDAES)-Universidad Nacional de San Martín, Ciudad Autónoma de Buenos Aires.

ROJAS MACHADO, M. (2018): Territorios, fronteras y permeabilidades. Un análisis espacial de las relaciones sociales dentro de un pabellón psiquiátrico-penitenciario de la República Argentina. PUBLICAR-En Antropología y Ciencias Sociales, 0(25), 63-84.

ROJAS MACHADO, M. (2019): Cuerpo y socialización: Entre la cárcel y el hospital psiquiátrico. Avá. Revista de Antropología, 34, 75-100.

Rueschemeyer, D., \& Skocpol, T. (1996): States, Social Knowledge, and the Origins of Modern Social Policies. Recuperado de http://public.eblib.com/choice/publicfullrecord.aspx?p=4821867

SCHEPER-HUGHES, N. (1990): Three propositions for a critically applied medical anthropology. Social Science \& Medicine, 30(2), 189-197. https://doi.org/10.1016/02779536(90)90079-8

SOZZO, M. (1999): A manera de epílogo. Cuestiones de responsabilidad entre dispositivo penal y dispositivo psiquiátrico: Materiales para el debate desde Argentina. Delito y sociedad: revista de ciencias sociales, (13), 163-182.

SOZZO, M. (2015): Locura y crimen: Nacimiento de la intersección entre los dispositivos penal y psiquiátrico (1. ed). Ciudad Autónoma de Buenos Aires: Didot.

STRAUSS, A., FAGERHAUGH, S., SUCZEC, B., \& WEINER, C. (1997): Social Organization of Medical Work (Reprint edition). New Brunswick, N.J., U.S.A: Routledge.

SY, A. (2018): La medicalización de la vida: Hibridaciones ante la dicotomía Naturaleza/Cultura. Ciência \&amp; Saúde Coletiva, 23(5), 1531-1539. https://doi.org/10.1590/1413-81232018235.10212016.

SYKES, G., \& MATZA, D. (2008): Técnicas de neutralización: Una teoría de la delincuencia. Caderno CRH, 21(52), 163-171.

SZASZ, T. (1970): El mito de la enfermedad mental. Buenos Aires: Amorrortu. 
VALERO, A., \& FARAONE, S. (2016): Lo punitivo y lo terapéutico. Una experiencia desinstitucionalizadora en salud mental en el ámbito penitenciario de la provincia de Santa Fe (Argentina). Delito y Sociedad, 1(31), 93-111. https://doi.org/10.14409/dys.v1i31.5635

VÁZQUEZ ACUÑA, M. (2007): Violencia intramural: Su impacto en los derechos humanos de las personas en situación de encierro. En D. Míguez \& A. R. Isla, En los márgenes de la ley. Inseguridad y violencia en el cono sur. Buenos Aires: Paidos. VEZZETTI, H. (1985): La locura en Argentina, Argentina. Buenos Aires: Paidos. VEZZETTI, H. (1996): Aventuras de Freud en el país de los argentinos: De José Ingenieros a Enrique Pichon-Rivière. Paidós.

VISACOVSKY, S. (2002): El Lanús: Memoria y política en la construcción de una tradición psiquiátrica y psicoanalítica argentina. Buenos Aires: Alianza Editorial.

WORLD HEALTH ORGANIZATION (Ed.). (1995): Clasificación estadística internacional de enfermedades y problemas relacionados con la salud (Décima revisión. [10a rev.]). Washington, D.C: OPS, Oficina Sanitaria Panamericana, Oficina Regional de la Organización Mundial de la Salud. 